\title{
Radiation-induced lung damage promotes breast cancer lung- metastasis through CXCR4 signaling
}

\author{
Lynn Feys ${ }^{1}$, Benedicte Descamps ${ }^{2}$, Christian Vanhove ${ }^{2}$, Anne Vral ${ }^{3}$, Liv Veldeman ${ }^{4}$, \\ Stefan Vermeulen ${ }^{5}$, Carlos De Wagter ${ }^{4}$, Marc Bracke ${ }^{1}$ and Olivier De Wever ${ }^{1}$ \\ ${ }^{1}$ Department of Radiation Oncology and Experimental Cancer Research, Laboratory of Experimental Cancer Research, Ghent \\ University, Ghent, Belgium \\ 2 Department of Electronics and Information System, iMinds-IBiTech-MEDISIP, Ghent University, Ghent, Belgium \\ ${ }^{3}$ Department of Basic Medical Sciences, Physiology Group, Ghent University, Ghent, Belgium \\ ${ }^{4}$ Department of Radiation Oncology and Experimental Cancer Research, Gent University Hospital, Ghent, Belgium \\ ${ }^{5}$ Department of Biomedical Science, HoGent, Ghent, Belgium
}

Correspondence to: Olivier De Wever, email: Olivier.dewever@ugent.be

Keywords: radiotherapy, triple-negative breast cancer, CXCL12, MIF, AMD3100

Received: July 22, $2015 \quad$ Accepted: August 29, $2015 \quad$ Published: September 15, 2015

This is an open-access article distributed under the terms of the Creative Commons Attribution License, which permits unrestricted use, distribution, and reproduction in any medium, provided the original author and source are credited.

\section{ABSTRACT}

Radiotherapy is a mainstay in the postoperative treatment of breast cancer as it reduces the risks of local recurrence and mortality after both conservative surgery and mastectomy. Despite recent efforts to decrease irradiation volumes through accelerated partial irradiation techniques, late cardiac and pulmonary toxicity still occurs after breast irradiation. The importance of this pulmonary injury towards lung metastasis is unclear. Preirradiation of lung epithelial cells induces DNA damage, p53 activation and a secretome enriched in the chemokines SDF-1/CXCL12 and MIF. Irradiated lung epithelial cells stimulate adhesion, spreading, growth, and (transendothelial) migration of human MDA-MB-231 and murine 4T1 breast cancer cells. These metastasis-associated cellular activities were largely mimicked by recombinant CXCL12 and MIF. Moreover, an allosteric inhibitor of the CXCR4 receptor prevented the metastasis-associated cellular activities stimulated by the secretome of irradiated lung epithelial cells. Furthermore, partial (10\%) irradiation of the right lung significantly stimulated breast cancer lung-specific metastasis in the syngeneic, orthotopic 4T1 breast cancer model.

Our results warrant further investigation of the potential pro-metastatic effects of radiation and indicate the need to develop efficient drugs that will be successful in combination with radiotherapy to prevent therapy-induced spread of cancer cells.

\section{INTRODUCTION}

Postoperative radiotherapy reduces the risk of both recurrence and mortality of breast cancer, and is nowadays standard treatment in the management of breast cancer after conservative surgery and after mastectomy to anticipate the high risk of relapse [1,2]. Despite this progress, locoregional post radiotherapy relapses still occur in about $7-12.6 \%$ of the patients within the 5 years after treatment [3-5]. Relapses occurring within a preirradiated area are associated with an increased risk of local invasion, metastasis formation and poor prognosis compared to relapses occurring outside of the irradiated area [6]. Recent experimental evidence supports these clinical observations. In murine xenograft models, tumors developing within preirradiated beds are more invasive and metastatic compared to tumors growing outside irradiated beds, a condition also referred to as "tumor bed effect". Kuonen et al. investigated cellular and molecular mechanisms underlying the tumor bed effect in breast cancer by using the 4T1 triple-negative murine model mimicking local relapse after radiotherapy and identified the role of cancer cells and mobilized myeloid cells as a metastasis promoting mechanism in breast [7]. Also, 
radiation-induced stemness of residual breast cancer cells increased spontaneous lung metastasis [8].

Although these experimental models adequately address the impact of the local tumor bed effect, these in vivo models do not consider the incidental exposure of the cardiopulmonary region to ionizing radiation after postoperative radiotherapy. Incidental cardiopulmonary irradiation is clinically important since it increases the subsequent rate of ischemic heart disease and secondary lung cancer risk $[9,10]$. Radiotherapy regimens for breast cancer have changed since these trials; the doses of up to 15 Gy to which the cardiopulmonary region was exposed are now generally lower $[9,10]$. Nevertheless, in most women receiving contemporary radiotherapy protocols, the cardiopulmonary region receives doses of 1 to 10.9 Gy [11]. The estimated percentage of total irradiated lung volume may range from 2.7 to $17.6 \%$ in a study population receiving tangential radiation beams [12].

Lungs are a prime target organ for breast cancer metastasis but the impact of incidental radiation exposure on lung metastasis is unknown. In this paper, we experimentally and molecularly addressed whether preirradiation of lung epithelial cells impacts metastasisassociated cellular activities of well-characterized triplenegative human MDA-MB-231 and murine 4T1 breast cancer cells. Using a murine xenograft model, lung metastasis formation was evaluated after exposure of $10 \%$ volume of the right lung to clinically relevant doses of radiation.

\section{RESULTS}

\section{Radiation effects on damage response and senescence markers in normal lung microenvironments}

To assess treatment-induced damage response in normal cells of the lung microenvironment, we examined mouse lung tissue that was excised 15 minutes after receiving thoracic sham or $10 \mathrm{~Gy}$ irradiation. We found evidence of DNA damage in lung epithelial cells as determined by the phosphorylation of histone H2AX on Ser139 $(\gamma \mathrm{H} 2 \mathrm{AX})$ within 15 minutes after 10 Gy irradiation (Figure 1A). To further ascertain the consequence of DNA damage in benign cells, we established an in vitro model treating Beas-2B epithelial cells of the lung microenvironment with a 10 Gy single radiation dose which substantially increased the number of $\gamma \mathrm{H} 2 \mathrm{AX}$ foci (Figure 1B). Irradiated cells showed no increase in cell death (Figure 1C, lower panel), but showed a more spread morphology with enlarged nuclei and increased cytoplasmic surface area (Figure 1C, upper panel). Furthermore, activation of p53 and increased expression of the p21 cell cycle arrest protein were observed (Figure
1D, Supplementary Figure S1). An indicator of cellular senescence, p21, was maintained up to 4 days after irradiation, which explains the lower number of cells (Figure 1B, 1C and 1D).

\section{Impact of irradiated lung epithelial cells on breast cancer cell growth and adhesion}

Irradiated or sham-irradiated Beas-2B cells were grown in co-culture with 4T1 luc or MDA-MB-231GFP luc triple-negative breast cancer cells and cancer cell growth was monitored by measuring luciferase activities after 4 days of co-culture. Co-culture with irradiated Beas-2B cells significantly enhanced the relative cancer cell growth 1.7-and 2.8-fold respectively compared to coculture with unirradiated Beas-2B cells (4T1_luc: sham vs. $10 \mathrm{~Gy}: 1.000 \pm 0.030$ vs. $1.740 \pm 0.172 ; \bar{P}<0.001$; MDA-MB-231GFP luc: sham vs. $10 \mathrm{Gy:} 1.000 \pm 0.067$ vs. $2.806 \pm 0.203 ; P \overline{<} 0.001$ ) (Supplementary Figure S2A, Figure 2A).

To study the effect on cancer cell adhesion, we seeded breast cancer cells on a monolayer of Beas2B epithelial cells 24 hours after irradiation or shamirradiation. Co-culture with irradiated Beas-2B cell monolayer significantly increased adhesion of both cancer cells 1.7-and 1.3-fold respectively compared to co-culture with unirradiated Beas-2B cell monolayer (4T1 luc: sham vs. $10 \mathrm{Gy:} 1.000 \pm 0.068$ vs. $1.66 \pm 0.3211 ; \bar{P}<0.001$; MDA-MB-231GFP_luc: sham vs. $10 \mathrm{Gy:} 1.000 \pm 0.182$ vs. $1.328 \pm 0.210 ; P<0.001$ ) (Supplementary Figure S2B, Figure 2B).

\section{Impact of soluble factors derived from irradiated lung epithelial cells on breast cancer cell morphology, growth, migration and extravasation}

To further investigate these effects we collected conditioned medium of unirradiated $\left(\mathrm{CM}^{\mathrm{LE}}\right)$ and irradiated Beas-2B cells $\left(\mathrm{CM}^{\mathrm{LE}-\mathrm{IR}}\right)$. Incubation of 4T1_luc and MDA-MB-231GFP_luc cells with $\mathrm{CM}^{\mathrm{LE}}{ }_{-}{ }_{\mathrm{IR}}$ significantly increased relative cell growth 1.8-and 1.9-fold respectively compared to incubation with $\mathrm{CM}^{\mathrm{LE}}$ (Supplementary Figure S2C, Figure 2C) $\left(\mathrm{CM}^{\mathrm{LE}}\right.$ vs. $\mathrm{CM}^{\mathrm{LE}} \mathrm{IR} ; 4 \mathrm{~T} 1$ luc: $1.000 \pm$ 0.314 vs. $1.800 \pm 0.730 ; P<0.001$; MDA-M̈-231GFP luc: $1.001 \pm 0.159$ vs. $1.891 \pm 0.569 ; P<0.001)$.

F-Actin staining of single cells revealed a more elongated morphology upon $\mathrm{CM}^{\mathrm{LE}}{ }_{-}^{\mathrm{IR}}$ compared to $\mathrm{CM}^{\mathrm{LE}}$ (Figure 2D, lower panel). This is shown by an increase in mean factor shape of MDA-MB-231GFP_luc cells incubated with $\mathrm{CM}^{\mathrm{LE}}{ }_{-} \mathrm{IR}$, this was 2.2-fold higher compared to the $\mathrm{CM}^{\mathrm{LE}}$ condition $\left(\mathrm{CM}^{\mathrm{LE}}\right.$ vs. $\mathrm{CM}^{\mathrm{LE}-\mathrm{IR}}: 3.742 \pm 1.686$ vs. $8.240 \pm 2.197 ; P<0.001$ ) (Figure 2D, upper panel).

Morphological changes suggest an impact on the migratory potential of cells. To investigate the effect of irradiated epithelial cells on breast cancer cell migration 

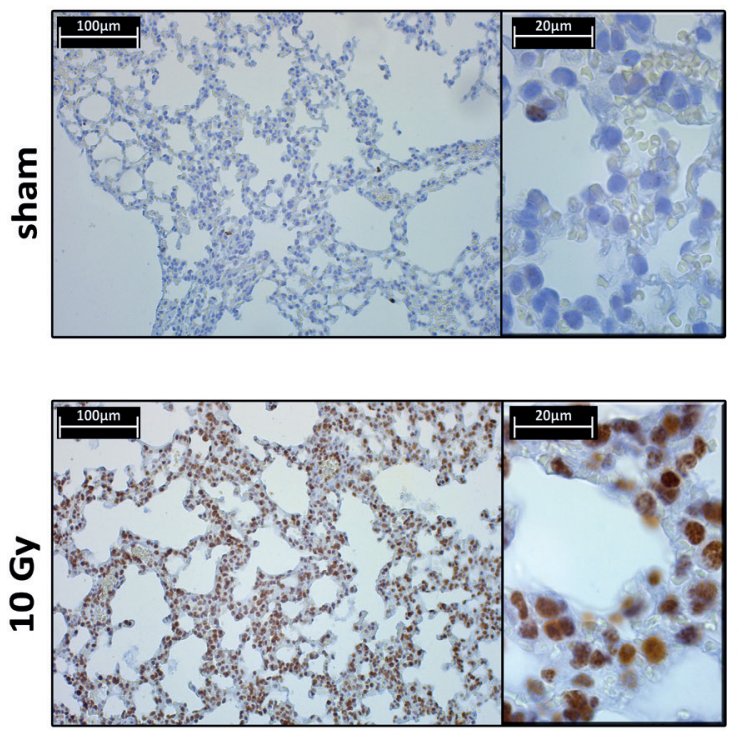
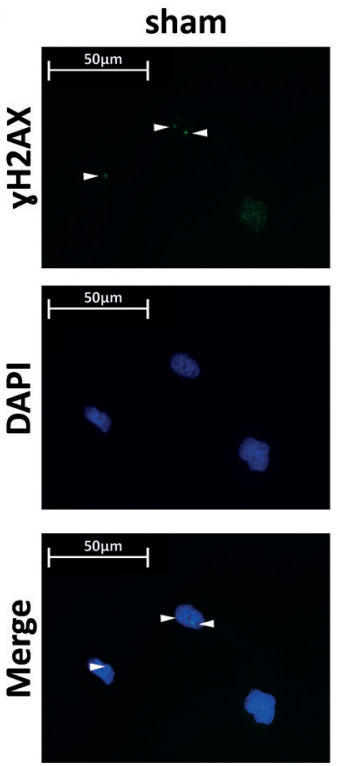

D
C
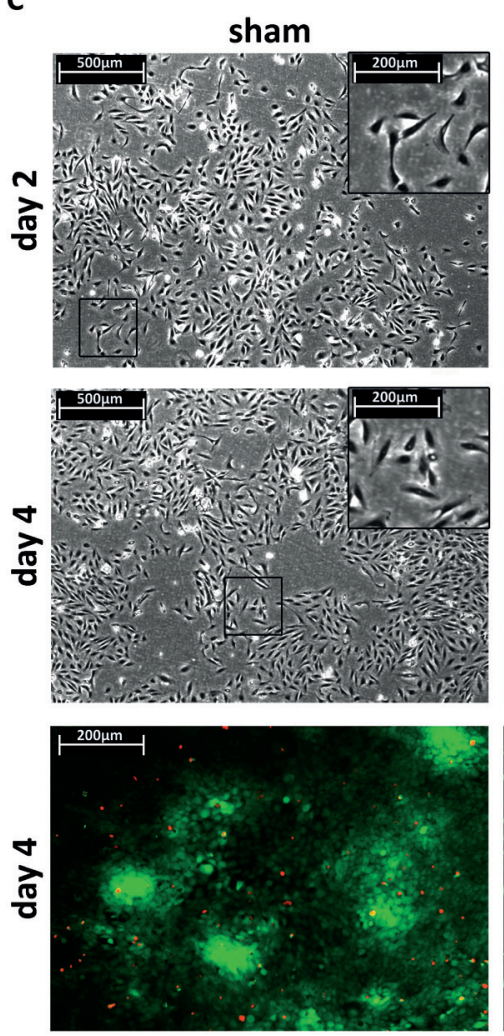

$10 \mathrm{~Gy}$
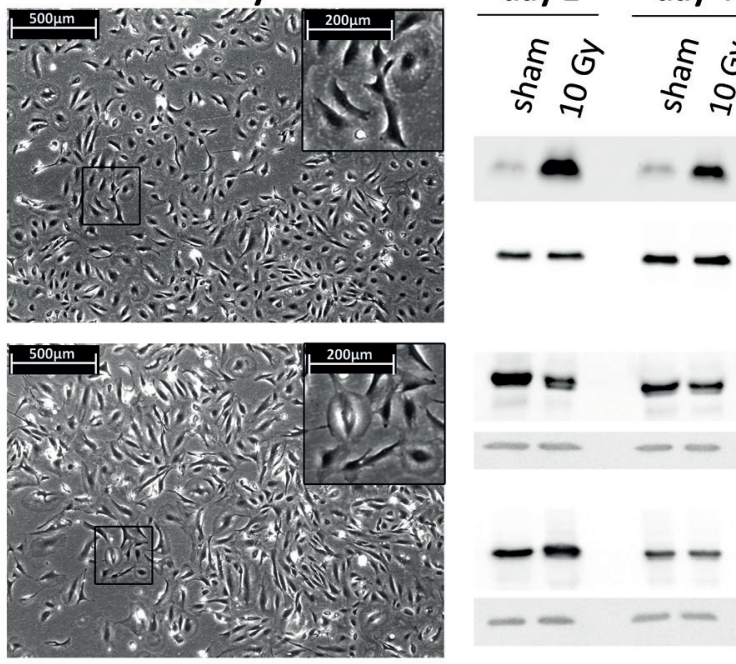

p53

GAPDH

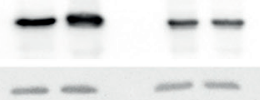

Pp53

GAPDH

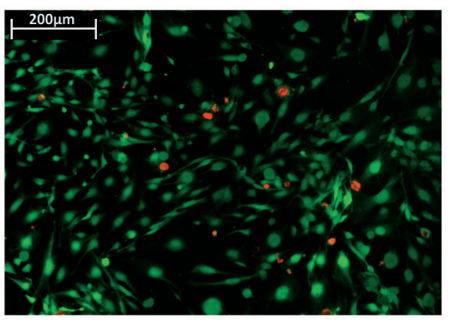

Figure 1: Lung epithelial cells radiation response and senescence markers. A. Immunohistochemical (IHC) staining of $\mathrm{\gamma H} 2 \mathrm{AX}$ foci using an immunoenzymatic DAB staining method (brown color) combined with a haematoxylin counterstaining in sham or 10 Gy irradiated mouse lung tissue. B. Immunocytochemical (ICC) staining of $\gamma \mathrm{H} 2 \mathrm{AX}$ foci (Alexa488 labeled secondary antibody, green color) combined with a DAPI nuclear counterstaining (blue color) in sham or 10 Gy irradiated Beas-2B lung epithelial cells. C. Upper 4 panels, phase contrast micrographs of Beas-2B lung epithelial cells two or four days post sham or 10 Gy irradiation. The 10 Gy condition shows less dense cell culture, a more spread cell morphology with enlarged nuclei and increased cytoplasmic surface area. Lower 2 panels, live/dead - viability/cytotoxicity test. Assay shows live cells as green and dead cells as red. Four days after single irradiation dose of 10 Gy shows no increase of Beas-2B cell death. D. Western blot (WB) analysis of p53 and p21 on total cell lysates from Beas-2B cells treated with single-fraction $10 \mathrm{~Gy}$ or sham. Total $\mathrm{p} 53$ expression is unchanged after irradiation but increase in p53 phosphorylation is observed at day 1 after treatment and normalizes at day 4 . Total expression of $\mathrm{p} 21$ is increased until day 4. GAPDH and tubulin are used as loading control. 


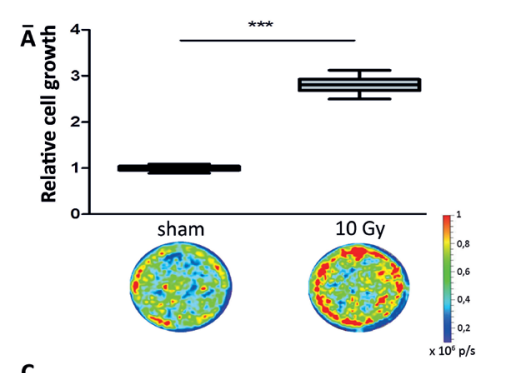

B
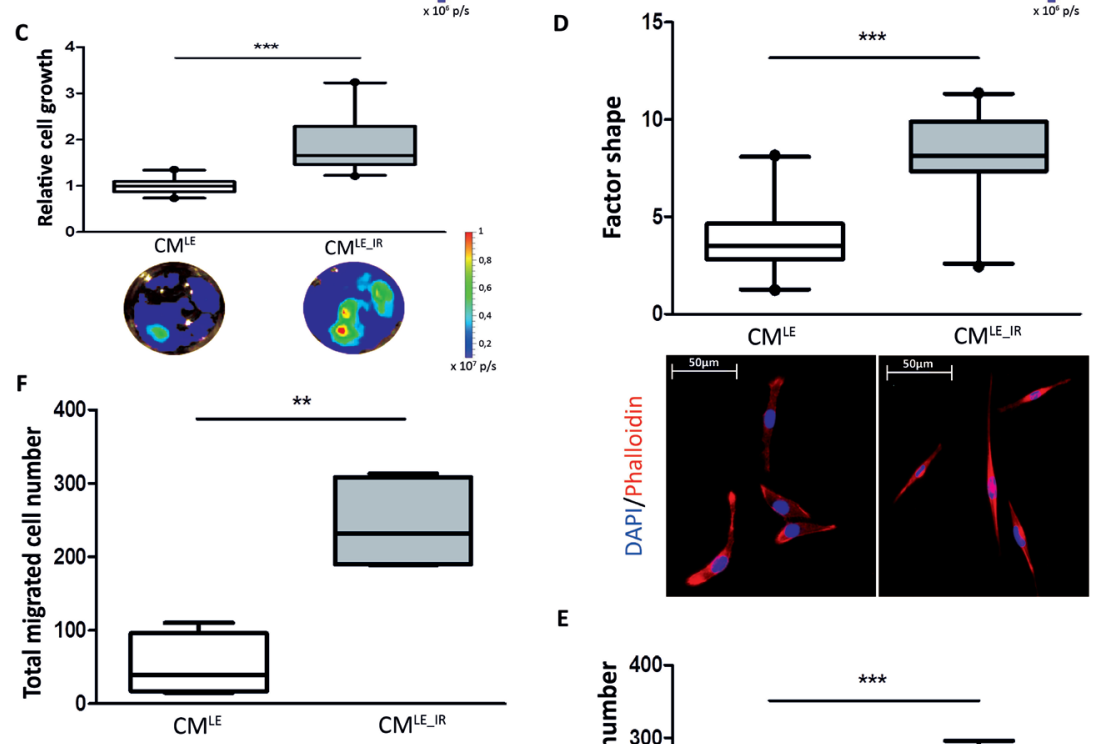

E
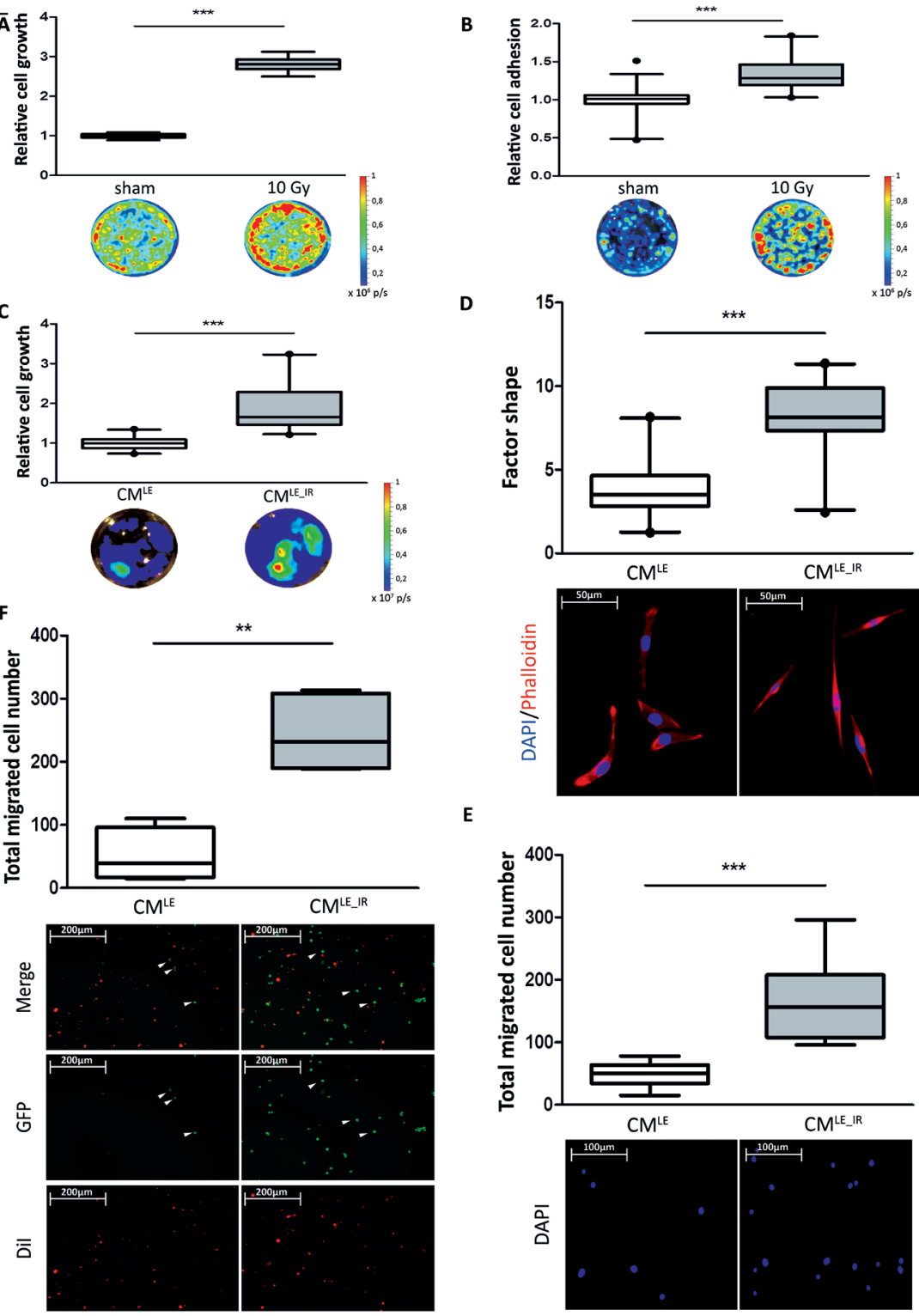

Figure 2: Impact of irradiated lung epithelial cells on breast cancer cell adhesion and growth. A. Box plots illustrating the relative cell growth of MDA-MB-231GFP_luc cells. Co-culture of breast cancer with irradiated Beas-2B cells increases relative cell growth compared to co-culture with sham treated Beas-2B cells. Quantification by bioluminescent imaging after 4 days incubation. Data is represented as relative fold change compared with the corresponding control value. MDA-MB-231GFP_luc: $n=6$; ***, $P<0.001$ (Unpaired $t$-test with Welch's correction). B. Box plots illustrating the relative cell adhesion of MDA-MB-231GFP_luc cells. Relative Adhesion of breast cancer cells to irradiated Beas-2B cell monolayer is increased compared to sham treated Beas-2B cell monolayer. Quantification by bioluminescent imaging after 24 hours incubation. Data is represented as relative fold change compared with the corresponding control value. MDA-MB-231GFP_luc: $n=15$; ***, $P<0.0001$; circle $=$ outlier (Unpaired $t$-test with Welch's correction). Impact of $C M^{L E}{ }_{-I R}$ on breast cancer cell morphology, growth, migration and extravasation. C. Box plots illustrating the relative cell growth of MDA-MB-231GFP_luc cells. Treatment of breast cancer cells with CM ${ }^{\mathrm{LE}}{ }_{\text {IR }}$ increases relative cell growth compared to cells treated with $\mathrm{CM}^{\mathrm{LE}}$. Quantification by bioluminescent imaging after 4 days incubation. Data is represented as relative fold change compared with the corresponding control value $\left(\mathrm{CM}^{\mathrm{LE}}\right)$. MDA-MB-231GFP_luc: $n=21 ; * * *, P<0.001$ (Mann-Whitney U). D. Box plots illustrating the extent of cell spreading of MDA-MB-231GFP_luc cells in $\mathrm{CM}^{\mathrm{LE} \_\mathrm{IR}}$ versus $\mathrm{CM}^{\mathrm{LE}}$ conditions, as quantified by factor shape (upper panel). Treatment with $\mathrm{CM}^{\mathrm{LE} \_\mathrm{IR}}$ showed enhanced cell spreading, corresponding with the significantly altered cell shapes (lower panel). Fluorescence microscopy images of cells double stained with phalloidin for actin filaments (red) and DAPI counterstaining for nuclei (blue) after 4 days of incubation with $\mathrm{CM}^{\mathrm{LE} \_\mathrm{IR}}$ versus $\mathrm{CM}^{\mathrm{LE}} . n=20$; *** $P<0.001$ (Mann-Whitney $\mathrm{U}$ ). E. Box plots illustrating total migrated cell number of MDA-MB-231GFP_luc cells in $\mathrm{CM}^{\mathrm{LE}} \mathrm{IR}$ versus $\mathrm{CM}^{\mathrm{LE}}$ conditions (upper panel). Nuclei of migrated cells were stained blue by DAPI (lower panel). $n=12$; ***, $P<0.001$ (Unpaired $t$-test with Welch's correction). F. Box plots illustrating total migrated cell number of MDA-MB-231GFP_luc cells through endothelial monolayer in $\mathrm{CM}^{\mathrm{LE} \_\mathrm{IR}}$ versus $\mathrm{CM}^{\mathrm{LE}}$ conditions (upper panel). $\mathrm{CM}^{\mathrm{LE} \_\mathrm{IR}}$ enhances breast cancer cell extravasation significantly. Endothelial cells were stained red with Vibrant DiI. Extravasated MDA-MB-231GFP_luc cells are green (lower panel). $n=6 ; * *, P=0.0022$ (Mann-Whitney U). Arrowheads indicating GFP positive migrated breast cancer cells. 
we employed TransWell ${ }^{\circledR}$ culture chambers separated into two compartments by microporous filters. In the lower compartment $\mathrm{CM}^{\mathrm{LE}}$ or $\mathrm{CM}^{\mathrm{LE}}{ }_{\mathrm{IR}}$ was added, while on top MDA_MB-231GFP_luc cells were seeded. As shown in Figure 2E, the directed migration of MDA-MB-231GFP luc cells was significantly increased by 3.4 -fold in the cells in presence of $\mathrm{CM}^{\mathrm{LE}}{ }_{-\mathrm{IR}}$ compared to those of $\mathrm{CM}^{\mathrm{LE}}\left(\mathrm{CM}^{\mathrm{LE}}\right.$ vs. $\mathrm{CM}^{\mathrm{LE} \_\mathrm{IR}}: 49.46 \pm 18.52$ cells $v s .166 .70 \pm 60.75$ cells; $P<0.001)$.

Extravasation, the migration of cancer cells through the endothelial wall into the target parenchyma, is another critical step in metastasis. This functional activity was biomimicked by studying directed breast cancer cell migration to $\mathrm{CM}^{\mathrm{LE}}$ or $\mathrm{CM}^{\mathrm{LE}} \mathrm{IR}^{\mathrm{R}}$ through a monolayer of endothelial cells. Under $\mathrm{CM}^{\mathrm{LE}}{ }_{-}^{\mathrm{IR}}$ conditions 4.7-fold more MDA-MB-231GFP_luc migrated through the endothelial layer compared to $\overline{\mathrm{C}} \mathrm{M}^{\mathrm{LE}}$ conditions $\left(\mathrm{CM}^{\mathrm{LE}}\right.$ vs. $\mathrm{CM}^{\mathrm{LE}} \mathrm{IR}^{\mathrm{IR}}$ : $52.00 \pm 39.69$ cells $v s .243 .70 \pm 57.25$ cells; $P=0.002)$ (Figure 2F, Arrowheads in $\mathrm{CM}^{\mathrm{LE}}$ point to migrated cancer cells.).

Summarized, we have shown that the secretome of irradiated Beas-2B lung epithelial cells contains factors that reorganize breast cancer cells to a more elongated shape and increase growth, migration and extravasation of the cancer cells.
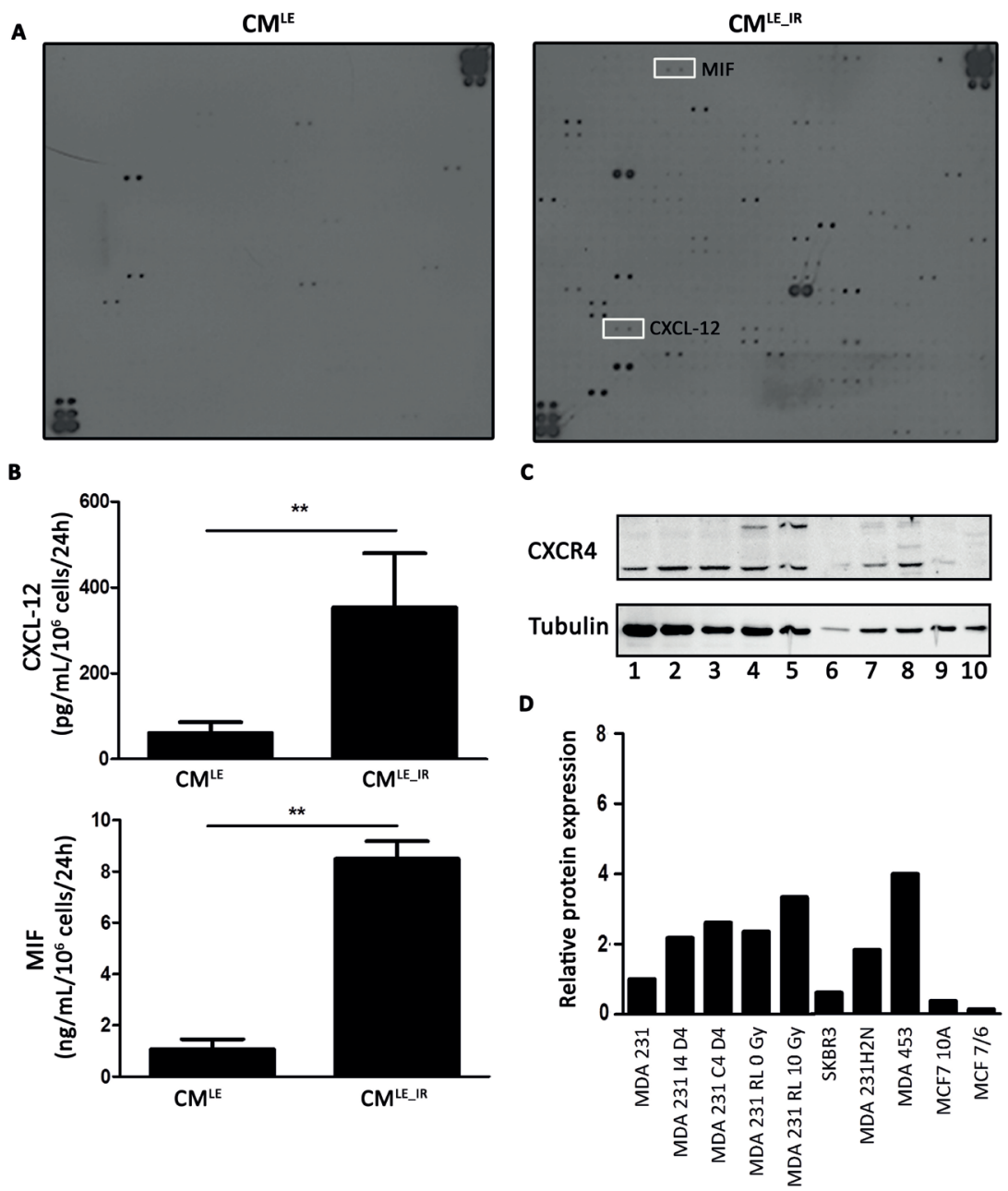

Figure 3: Increased secretion of CXCL12 and MIF by irradiated lung epithelial cells. A. Cytokine array identifies enhanced presence of CXCL12 and MIF in $\mathrm{CM}^{\mathrm{LE}}{ }_{-} \mathrm{IR}$ compared to CM ${ }^{\mathrm{LE}}$. B. ELISA analysis of CXCL12 (upper panel) and MIF (lower panel) on $\mathrm{CM}^{\mathrm{LE} \_\mathrm{IR}}$ versus $\mathrm{CM}^{\mathrm{LE}}$. For each condition 2 different samples were used in triplicate. Values are presented as the mean $\pm \mathrm{SD}$. CXCL12: **, $P=0.010$. MIF: **, $P=0.004$ (Mann-Whitney U). C. Western blot analysis of CXCR4 expression on total lysate of breast cancer cells. Lane 1-5, represents MDA-MB-231GFP_luc (invasive cell line) in different conditions (MDA 231: parental MDA-MB-231GFP_luc; MDA 231 I4 D4: MDA 231 cells exposed to $\mathrm{CM}^{\mathrm{LE} \_} \mathrm{IR}$ for 4 days; MDA $231 \mathrm{C} 4$ D4: MDA 231 cells exposed to CM ${ }^{\mathrm{LE}}$ for 4 days; MDA 231 RL 0 Gy: MDA 231 isolated from non-irradiated mouse lung; MDA $231 \mathrm{RL} 10 \mathrm{~Gy}$ : MDA 231 isolated from irradiated mouse lung. Lane 6: SKBR3 (non-invasive cell line). Lane 7: MDA-MB-231H2N (invasive cell line). Lane 8: MDA-MB-453 (invasive cell line). Lane 9: MCF 10A (non-invasive cell line). Lane 10: MCF7/6 (non-invasive cell line). D. Quantitative analysis CXCR4 protein expression level. Western blot analysis of CXCR4 protein expression in different breast cancer cell lines after tubulin normalization. Protein levels relative to control, MDA-MB-231GFP_luc. 


\section{Increased secretion of CXCL12 and MIF by irradiated lung epithelial cells}

The composition of $\mathrm{CM}^{\mathrm{LE}}$ and $\mathrm{CM}^{\mathrm{LE}}{ }^{\mathrm{IR}}$ was assessed to determine which cytokines were secreted by unirradiated versus irradiated lung epithelial cell. Semi-quantitative results from a cytokine array showed that $\mathrm{CM}^{\mathrm{LE}} \mathrm{IR}^{\mathrm{IR}}$ contained a total of 52 cytokines with a signal that exceeded that of $\mathrm{CM}^{\mathrm{LE}}$ condition (Figure 3A; Supplementary Table S1). We selected the CXCL12 and MIF cytokines for further study because of a high fold change (more than 80 -fold) and a known role in breast cancer metastasis [13]. CXCL12 and MIF, which had an 83.88-and 86.46-fold higher presence, respectively, in $\mathrm{CM}^{\mathrm{LE}}{ }^{\mathrm{IR}}$ compared to $\mathrm{CM}^{\mathrm{LE}}$ (Supplementary Table 1). Responding to fold changes (relative changes) rather than absolute change is intrinsically important in chemokine attraction and consequently regulation of metastasis [14, 15]. Quantitative ELISA data showed that irradiated lung epithelial cells had a secretion of CXCL12 and MIF that is 5.8-and 7.9-fold higher, respectively, than unirradiated lung epithelial cells (Figure 3B) $\left(\mathrm{CM}^{\mathrm{LE}}\right.$ vs. $\mathrm{CM}^{\mathrm{LE}}{ }_{-} \mathrm{R}$; CXCL12: $61.07 \pm 12.59$ vs. $353.70 \pm 126.00 \mathrm{pg} / \mathrm{mL} / 10^{6}$ cells/24h; $P=0.010$; MIF: $1.072 \pm 0.390 v s .8 .495 \pm 0.695$ $\mathrm{ng} / \mathrm{mL} / 10^{6}$ cells $\left./ 24 \mathrm{~h} ; P=0.004\right)$. According to previous literature, both cytokines may affect metastasis through activation of the CXCR4 receptor on cancer cells [13]. Western Blot analysis confirmed that cancer cell lines, that are known to have an invasive phenotype, have a higher expression of CXCR4 (45-47 kDa) (Figure 3C-3D)[16].

\section{Effect of recombinant CXCL12 and MIF on breast cancer cell growth and migration}

To verify if CXCL12 and MIF may contribute to the effects observed with the secretome of irradiated cells, the recombinant forms were supplemented to the secretome of unirradiated cells and used to assess the functional impact on cancer cells. $\mathrm{CM}^{\mathrm{LE}}$ supplemented with recombinant CXCL12 or MIF induced an increase in cell growth as demonstrated for MDA-MB-231GFP_luc cells (Figure 4A) $\left(\mathrm{CM}^{\mathrm{LE}}\right.$ vs. $\mathrm{CM}^{\mathrm{LE}}+\mathrm{CXCL12:} 1.002 \pm 0.157$ vs. 1.807 $\pm 0.241 ; P<0.001 ; \mathrm{CM}^{\mathrm{LE}} v s . \mathrm{CM}^{\mathrm{LE}}+\mathrm{MIF}: 1.002 \pm 0.157$ vs. $2.010 \pm 0.259 ; P<0.001)$ and induced an increase in cell migration after treatment with CXCL12 (Figure 4B) $\left(\mathrm{CM}^{\mathrm{LE}}\right.$ vs. $\mathrm{CM}^{\mathrm{LE}}+\mathrm{CXCL} 12: 48.830 \pm 18.640$ vs. $82.830 \pm$ $29.360 ; P=0.038)$. Experiments with MIF did not show significant difference in cancer cell migration (data not shown).

\section{Allosteric targeting of CXCR4 receptor reversed paracrine effect induced by irradiated epithelial cells}

To investigate whether the observed effects depend on activation of the CXCR4 receptor, AMD3100, an allosteric inhibitor of CXCR4 receptor, was used. Addition of AMD3100 reversed the pro-metastasis associated effects of $\mathrm{CM}^{\mathrm{LE}}{ }_{-} \mathrm{IR}$ such as relative cell growth (Figure 5A) $\left(\mathrm{CM}^{\mathrm{LE} \_ \text {IR }} v s . \mathrm{CM}^{\mathrm{LE}} \_\mathrm{IR}+\mathrm{AMD} 3100: 1.000 \pm 0.107 v s\right.$. $0.717 \pm 0.144 ; P<0.001$ ), relative adhesion (Figure 5B) $\left(\mathrm{CM}^{\mathrm{LE} \_ \text {IR }}\right.$ vs. $\mathrm{CM}^{\mathrm{LE} \_\mathrm{IR}}+\mathrm{AMD} 3100: 1.000 \pm 0.060$ vs. 0.665 $\pm 0.166 ; P<0.001)$, migration and extravasation of breast cancer cells (Figure 5C \& 5D) (Migration - $\mathrm{CM}^{\mathrm{LE} \_\mathrm{IR}} v s$. $\mathrm{CM}^{\mathrm{LE}} \_\mathrm{IR}+$ AMD3100: $162.40 \pm 74.62$ cells vs. $75.33 \pm$ 33.32 cells; $P=0.009$; Extravasation $-\mathrm{CM}^{\mathrm{LE} \_\mathrm{IR}} v s$. $\mathrm{CM}^{\mathrm{LE} \_\mathrm{IR}}$ + AMD3100: $243.70 \pm 57.25$ cells $v s .100 .40 \pm 57.11$ cells; $P=0.017)$. Furthermore, AMD3100 treatment partially reversed $\mathrm{CM}^{\mathrm{LE}} \_\mathrm{R}$-induced morphological changes, as measured by factor shape (Figure 5E) $\left(\mathrm{CM}^{\mathrm{LE} \_}{ }_{2} \mathrm{R} v s\right.$. $\mathrm{CM}^{\mathrm{LE}} \_\mathrm{IR}$ + AMD3100: $8.240 \pm 2.197$ vs. $5.243 \pm 2.772 ; P=0.004)$.

\section{Paracrine activation of ERK, Akt and STAT3 in breast cancer cells by $\mathrm{CM}^{\mathrm{LE} \_ \text {IR }}$ and recombinant CXCL12}

$\mathrm{CM}^{\mathrm{LE} \_ \text {IR }}$ activated multiple CXCR4-dependent downstream cascades, like ERK, Akt and STAT3, in MDA-MB-231GFP_luc cells (Figure 6A). These pathways are involved in mediating cellular proliferation, survival, migration, transformation and differentiation [17]. In agreement, addition of recombinant CXCL12 or MIF stimulated Akt, ERK and STAT3 activation, although an equal concentration of MIF showed a smaller increase than CXCL12 (Figure 6A, Supplementary Figure S3A).

Next, we examined the impact of Trametinib and AMD3100 on $\mathrm{CM}^{\mathrm{LE}}{ }_{\text {IR }}$-induced ERK, Akt and STAT3 activation. Previous literature showed that triple-negative breast cancer cells are the most sensitive for treatment with MEK inhibitor[18]. Nanomolar concentrations of Trametinib, an allosteric MEK1/2 inhibitor, completely blocked $\mathrm{CM}^{\mathrm{LE}} \mathrm{IR}$ induced ERK activation (Figure 6B, Supplementary Figure S3B) with no impact on AKT or STAT3 activation. Similar effects were observed when combining recombinant CXCL12 or MIF with Trametinib (Figure 6C-6D, Supplementary Figure S3C-D). In accordance with the functional experiments, AMD3100 decreased $\mathrm{CM}^{\mathrm{LE}}{ }_{-\mathrm{IR}}$-induced Akt and STAT3 pathway activation; a minor impact on pERK was observed in the cancer cells exposed with $\mathrm{CM}^{\mathrm{LE}} \_\mathrm{IR}+$ AMD3100 compared to $\mathrm{CM}^{\mathrm{LE}} \_\mathrm{IR}$ alone (Figure $6 \mathrm{~B}$ ). These effects with AMD3100 are less pronounced when $\mathrm{CM}^{\mathrm{LE}}$ is combined with recombinant CXCL12 and MIF (Figure 6C-6D, Supplementary Figure S3C-D). 


\section{Impact of partial lung irradiation on lung-specific breast cancer metastasis in a syngeneic mouse model}

A syngeneic, orthotopic triple-negative breast cancer model 4T1_luc was developed to study the impact of irradiation of the lung on the formation of lung metastasis. Patient studies showed that approximately $10 \%$ of the total lung volume is irradiated during breast cancer RT, with a mean lung dose of 10 Gy $[11,12]$. All groups of mice received CT scan radiation for the localization of lung tissue; in the sham treatment group, no further irradiation was performed; the WT group received a 10 Gy irradiation to the whole thorax; the PRL group (partial right lung) received a 10 Gy irradiation to approximately $18 \mathrm{~mm}^{3}$ part (10\% of total volume) of the right lung (Supplementary Figure S4-S5). 4T1 luc cells $\left(1 \times 10^{6}\right)$ were orthotopically injected 24 hours after irradiation. Neither WT nor PRL irradiation did significantly impact primary tumor growth (Figure 7A) (sham vs. 100\% IR vs. 10\% IR: $446 \pm 111$ $\mathrm{mm}^{3}$ vs. $471 \pm 63 \mathrm{~mm}^{3}$ vs. $\left.526 \pm 109 \mathrm{~mm}^{3}\right)$. Four weeks after orthotopic 4T1_luc breast cancer inoculation, all lungs were prelevated and bioluminescent activity in the

A

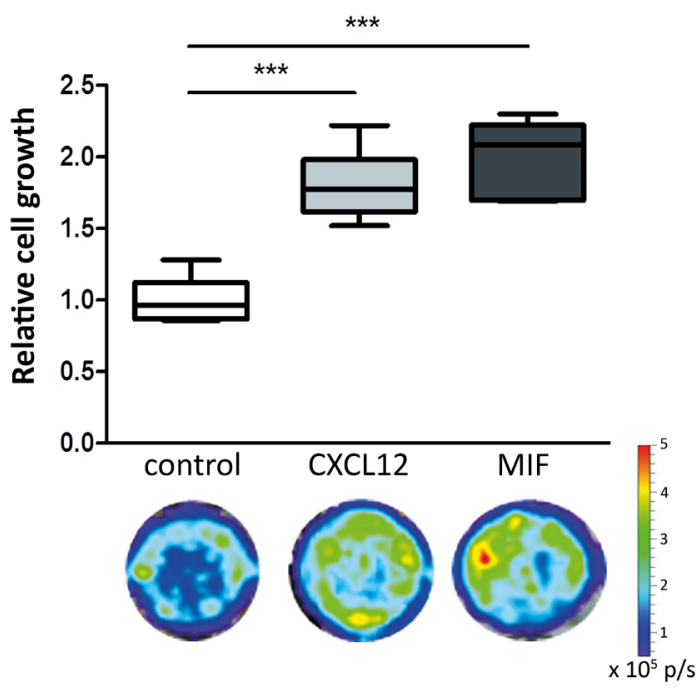

B

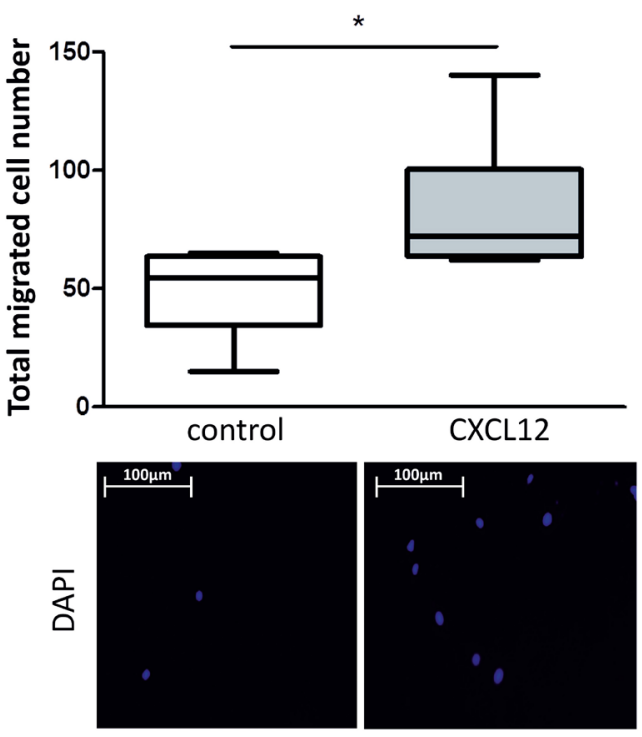

Figure 4: Effect of recombinant CXCL12 and MIF on breast cancer cell growth and migration. A. Box plots illustrating the relative cell growth of MDA-MB-231GFP_luc cells. Treatment of breast cancer cells with CXCL12 (50 ng/mL) or MIF (50 ng/mL) increases relative cell growth compared to control. Quantification by bioluminescent imaging after 4 days incubation. Data is represented as relative fold change compared with the corresponding control value $\left(\mathrm{CM}^{\mathrm{LE}}\right) . n=6$; $* * *, P<0.001$ (Unpaired $t$-test). B. Box plots illustrating difference in total migrated cell number of MDA-MB-231GFP_luc cells treated with CXCL12 (50 ng/mL) (upper panel). Nuclei of migrated cells were stained blue with DAPI (lower panel). $n=6 ;{ }^{*}, P=0.038$ (Unpaired $t$-test). 
A

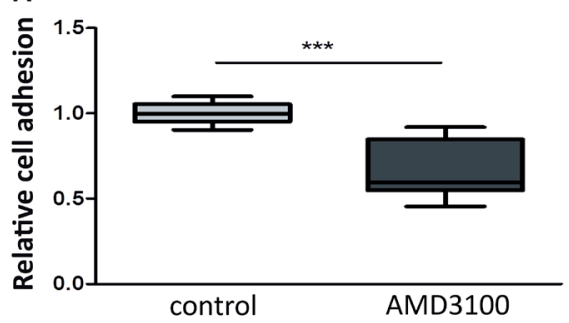

C

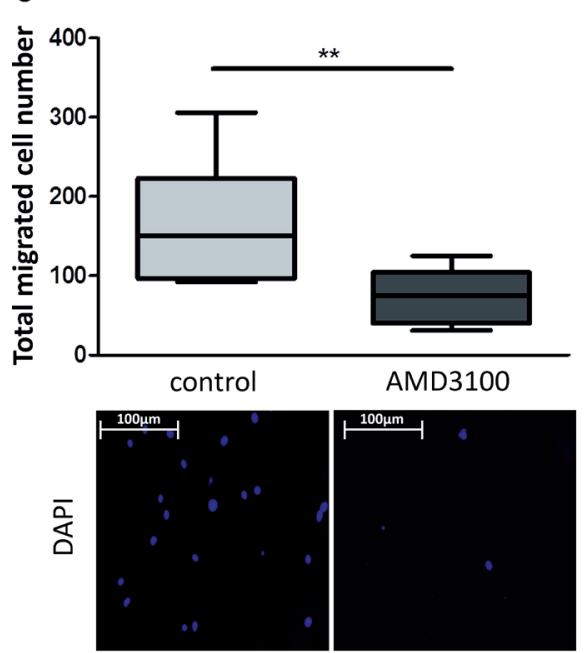

E

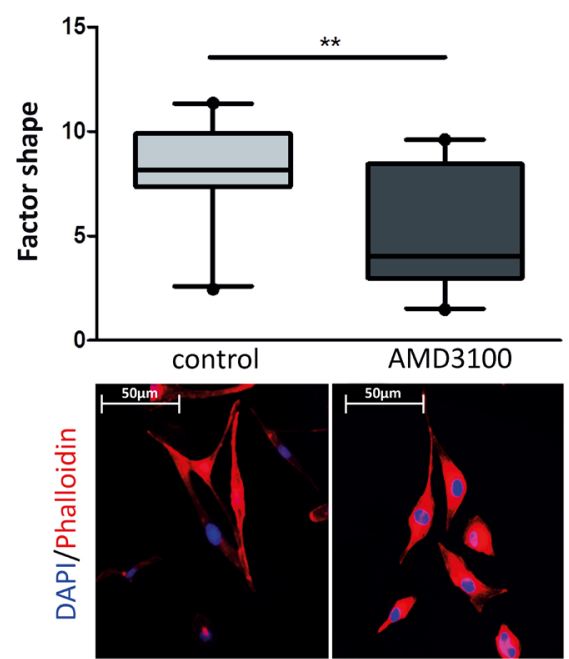

B

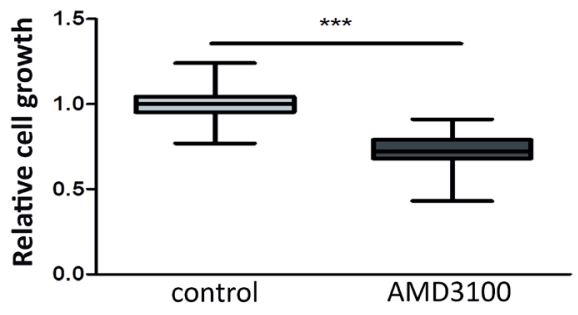

D

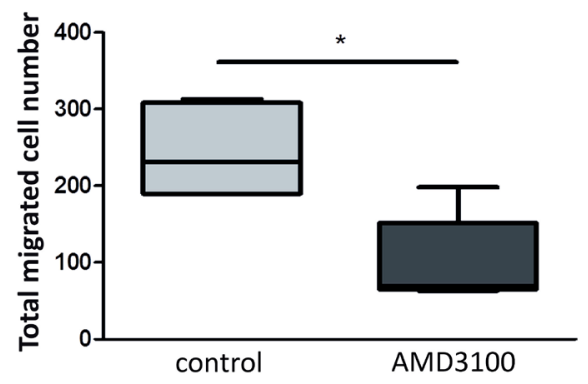

Figure 5: Effect of an allosteric CXCR4 inhibitor on breast cancer cell growth and migration. A. Box plots illustrating the relative cell adhesion of MDA-MB-231GFP_luc cells. Treatment of breast cancer cells with AMD3100 (10 $\mu \mathrm{M})$ decreases relative cell adhesion to irradiated Beas-2B cell monolayer. $n=12 ; * * *, P<0.001$ (Unpaired $t$-test with Welch's correction). B. Box plots illustrating the relative cell growth of MDA-MB-231GFP_luc cells. Treatment of breast cancer cells with AMD3100 $(10 \mu \mathrm{M})$ decreases relative cell growth in presence of $\mathrm{CM}^{\mathrm{LE}-\mathrm{IR}}$. (Unpaired $t$-test with Welch's correction). $n=15 ; * * *, P<0.001$ (Unpaired $t$-test). In C. and D., quantification by bioluminescent imaging after 4 days incubation. Data is represented as relative fold change compared with the corresponding control value. C. Box plots illustrating impact of AMD3100 $(10 \mu \mathrm{M})$ on total migrated cell number of MDA-MB-231GFP_luc cells stimulated by $\mathrm{CM}^{\mathrm{LE}-\mathrm{IR}}$. Nuclei were stained blue with DAPI (lower panel). $n=9 ; * *, P=0.009$ (Unpaired $t$-test with Welch's correction). D. Box plots illustrating total transendothelial migrated cell number of MDA-MB-231GFP_luc cells stimulated by CM ${ }^{\mathrm{LE}-\mathrm{IR}}$ in presence of AMD3100 (10 $\mu \mathrm{M}$ ) or control. $n=6$; $^{*}, P=0.017$ (Mann-Whitney U). E. Box plots illustrating the extent of CM ${ }^{\mathrm{LE}-\mathrm{IR}}$-induced cell spreading of MDA-MB231GFP_luc cells treated with AMD3100 $(10 \mu \mathrm{M})$ versus control, as quantified by factor shape (upper panel). Fluorescence microscopy images of cells double stained with phalloidin for actin filaments (red) and DAPI counterstaining for nuclei (blue) (lower panel). $n=20$; $* *, P=0.004$ (Mann-Whitney U). 
$\dot{A}$
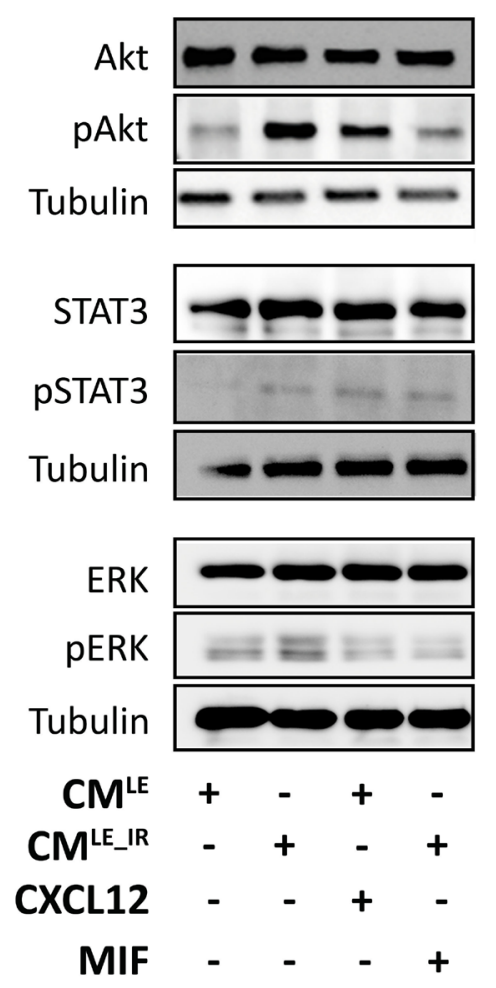

C
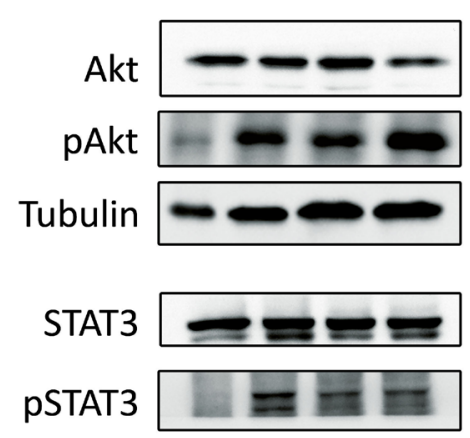

Tubulin
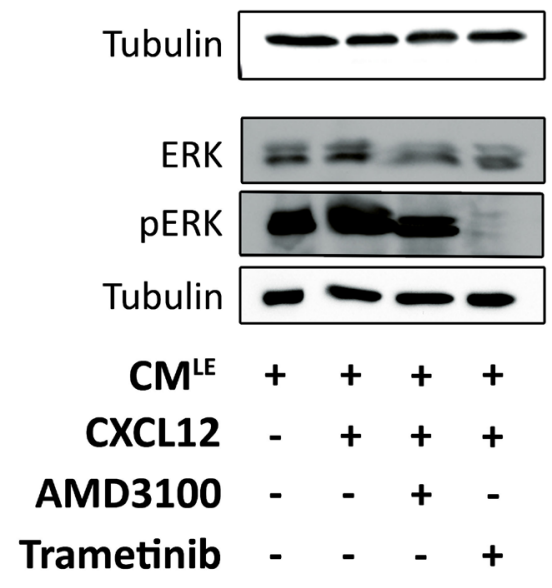

B
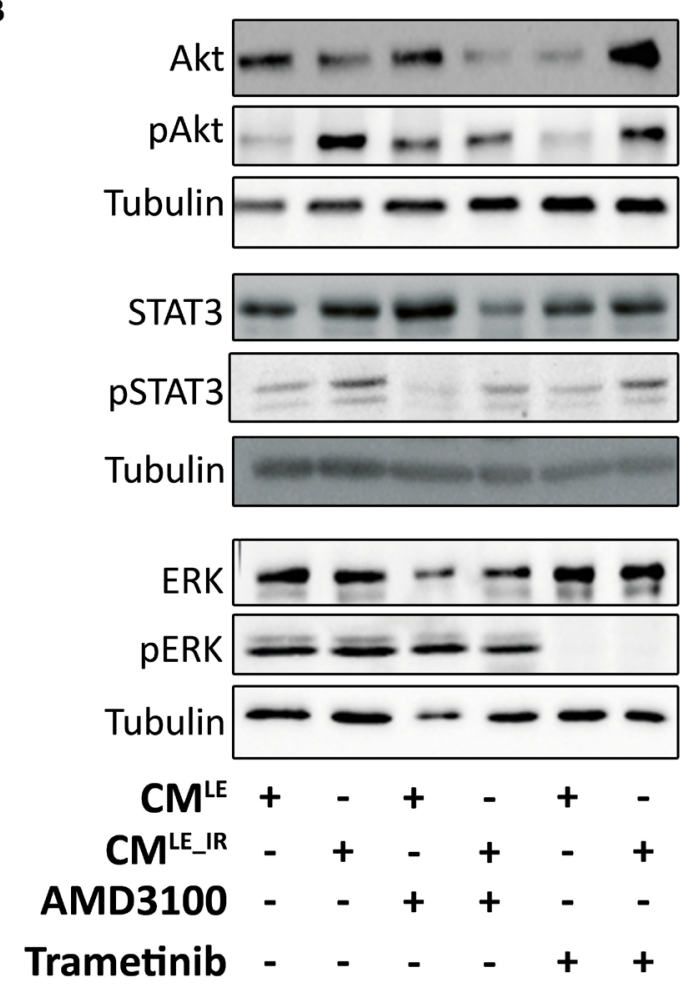

D
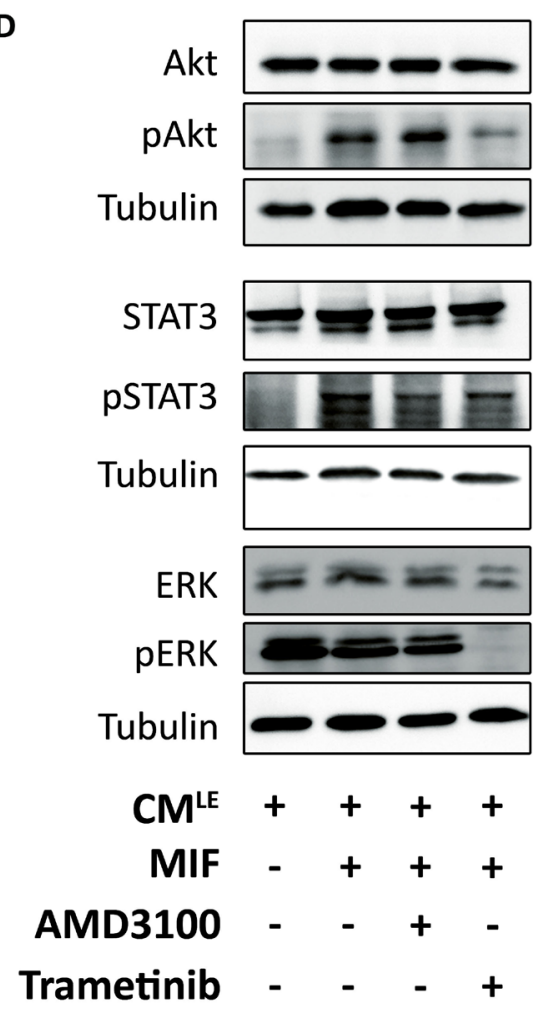

Figure 6: Paracrine activation of ERK, Akt and STAT3 in breast cancer cells by CM $^{\mathrm{LE}}$ IR and recombinant CXCL12. A.-D.. Western blot analysis of pERK, pAkt and pSTAT3 in MDA-MB-231GFP luc cells treated with recombinant CXCL12 (50 ng/mL) or MIF $(50 \mathrm{ng} / \mathrm{mL})$ A. CM ${ }^{\mathrm{LE}}, \mathrm{CM}^{\mathrm{LE}} \_\mathrm{IR}$, in presence of AMD3100 $(10 \mu \mathrm{M})$ or Trametinib $(50 \mathrm{nM})$ B. recombinant CXCL12 $(50 \mathrm{ng} / \mathrm{mL})$ C. or MIF $(50 \mathrm{ng} / \mathrm{mL})$ D. in presence of AMD3100 $(10 \mu \mathrm{M})$ or Trametinib $(50 \mathrm{nM})$ Tubulin is used as loading control. 
separate lungs was compared between the three groups. Mice which received a 10 Gy PRL irradiation showed more bioluminescent signal, and thus more metastasis, in each lung compared to WT irradiated or sham treated mice (Figure 7B). In addition, when only bioluminescent signal of those lungs with activity were included we observed significantly higher signals in the right lung of PRL irradiated mice compared to the right lung of sham treated mice, suggesting more metastatic growth $(P=0.043)$ (Figure 7C, Supplementary Figure S6); a similar trend was observed for the left lung but no significant value was reached. Semi-quantitative histological examination of metastatic lung tissue demonstrated more and larger metastasis in mice receiving PRL irradiation compared to sham or WT (Figure 7D, as illustration. Figure 7E, quantification). This was confirmed by quantitatively analyzing the total metastatic area between the groups. In sham groups an average metastatic area of $1.2 \%$ was reached, comparable to the WT irradiated group with an average area of $1.3 \%$. Both groups are remarkably, but not significantly, lower than the PRL irradiated group, with a three-fold increase of metastatic area (5.0\%) (Figure 7E). Moreover, comparing total lung bioluminescent signal (signal right and left lung as one), sham treated mice still had the lowest signal but WT irradiated mice and PRL irradiated mice showed a 2.1- and 7.1-fold increase, respectively, in signal (Figure 7F).

\section{DISCUSSION}

Because of the absence of oestrogen-, progesteroneand HER2 receptor [19], triple-negative breast cancers are not curable with hormonal treatment and HER2 therapies. Standard mastectomy or breast conserving surgery with adjuvant radio-and chemotherapy is used as a standard to treat this patients [20]. Postoperative radiotherapy of breast cancer reduces the risk of local recurrence and mortality after both conservative surgery and mastectomy $[1,2]$. Despite recent efforts to decrease irradiation volumes and improved irradiation techniques, late cardiac and pulmonary toxicity does still occur after breast irradiation $[6,11]$. The implications of this pulmonary injury for lung metastasis are unclear. A randomized trial in highrisk post-mastectomy patients showed that the long-term probabilities of lung metastases are significantly lower in the irradiated (RT) patients compared to non-irradiated (no-RT) patients. Interestingly, distant metastasis as first failure (independent from local relapse) was $47 \%$ in the RT group compared to $37 \%$ in the no-RT group, suggesting that lung metastasis do not necessarily occur after local relapse [21]. Although it is generally assumed in this case that micro-metastasis in the lungs were present before breast cancer was treated, an alternative, admittedly provocative, hypothesis is that radiation-induced collateral damage of the lung influences lung-specific metastasis. Metastasis can be an early event and stay undetected at time of diagnosis [22, 23]. Patients, presenting with micrometastasis, receive radiotherapy which can stimulate metastatic growth. The difference in our in vivo model is that we first irradiated the lung and waited for metastasis to grow [22]. Our model is not relevant for the effect of ionizing radiation on already established micro-metastasis because we graft syngeneic breast cancer cells after ionizing radiation. We radiate part of the right lung, graft syngeneic breast cancer cells and study the impact on spontaneous lung metastasis formation. Lung irradiation has no impact on orthotopic tumor growth. However, we observe more and bigger metastatic foci in the lungs of PRL mice which can be caused by increased attraction of circulating cancer cells and/or stimulation of cancer cell release from the primary tumor and/or preparation of the metastatic niche (promoting adhesion and colonization of breast cancer cells). Breast cancer patients who did receive post-mastectomy radiotherapy showed most often distant metastasis as first site of failure in contrast to patients who did not receive post-mastectomy radiotherapy, here locoregional relapse and distant metastasis as first site of failure were equally common [21]. Studies (using postmortem samplings) should be designed to investigate a potential relationship between collateral lung irradiationdamage and lung metastasis in breast cancer patients. The literature provides no level-one evidence because no randomized trials have been done correlating the dose indices of irradiated lung volumes with lung-specific metastasis in breast cancer. A clinical study with breast cancer patients undergoing postoperative radiation therapy of 50 Gy at $2 \mathrm{~Gy} /$ fraction, 5 days/week showed that the pulmonary region received a mean lung dose of approximately $10 \mathrm{~Gy}$. If more than 3 axillary lymph nodes were affected, a supraclavicular field was added with equal dose and fractionation resulting in a higher mean pulmonary dose of 15.8 Gy [11]. This collateral irradiation to the lungs resulted in reduced pulmonary function in the first two years after the postoperative radiotherapy.

Histone H2AX phosphorylation is a recognized marker of DNA damage, i.e. double strand breaks [24]. The manner how DNA responds to radiation damage, indicated by $\gamma \mathrm{H} 2 \mathrm{AX}$ foci, has been investigated in mice models receiving thoracic radiation and shown to be correlative with fibrosis in distressed mice [25]. In our experiments, sham-irradiated lung tissue sections of BALB/c mice were almost completely negative for $\gamma \mathrm{H} 2 \mathrm{AX}$ foci, whereas $10 \mathrm{~Gy}$ thoracic irradiation resulted in a massive increase in the number of pulmonary nuclei with $\gamma \mathrm{H} 2 \mathrm{AX}$ foci throughout the tissue sections, irrespective of cell type. In vitro experimentation on lung epithelial cells, the major pulmonary cell type, revealed potent $\mathrm{H} 2 \mathrm{AX}$ and $\mathrm{p} 53$ responses to radiation which coincided with morphological changes, induction of cellular senescence markers and an enhanced secretion of multiple chemokines and growth factors. Gunjal et al. demonstrated that ovarian cancer cells responding to heat- 

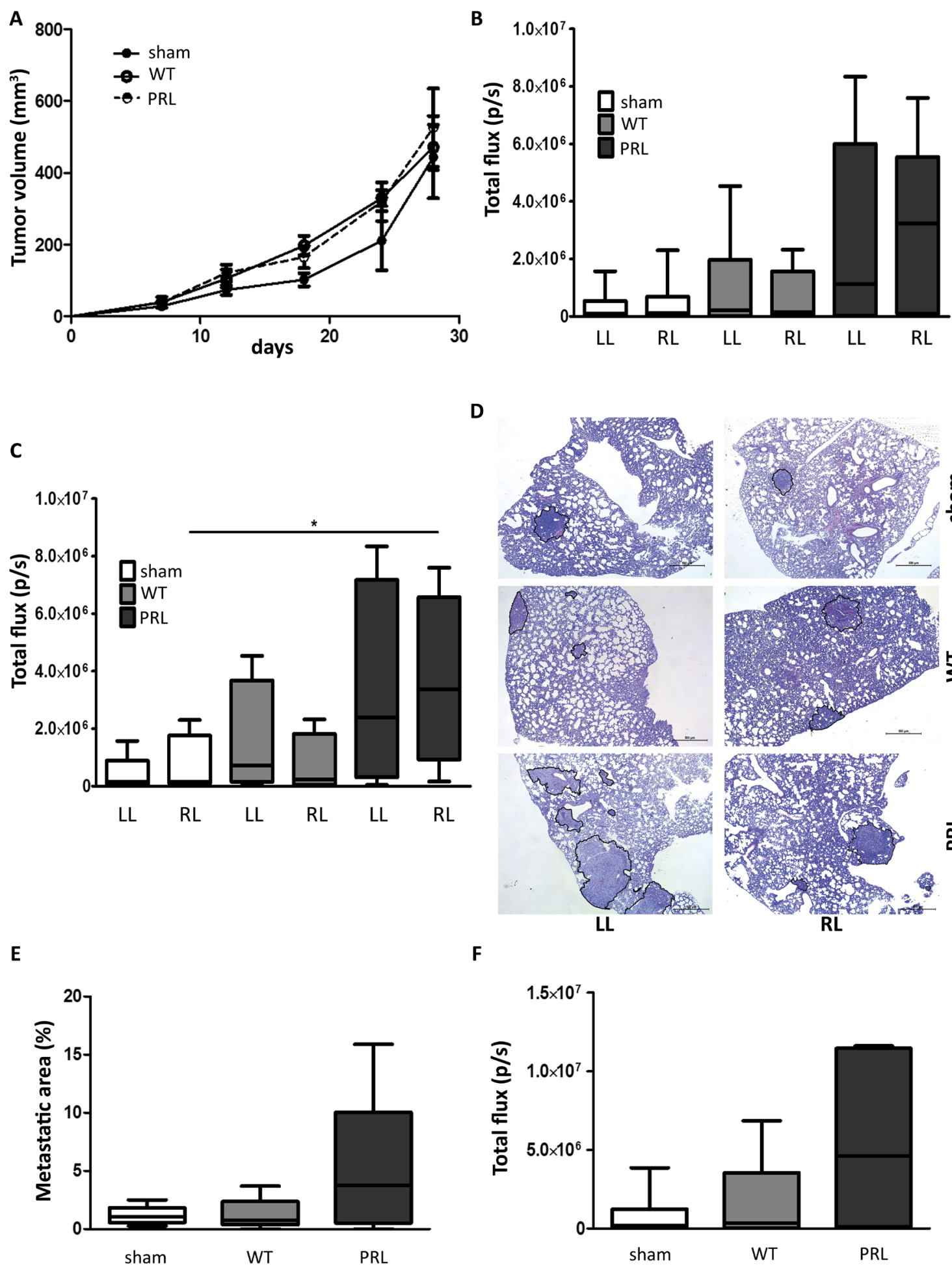

Figure 7: Impact of partial lung irradiation on lung-specific breast cancer metastasis in a syngeneic mouse model. A. 4 week old BALB/c female mice were injected orthotopically with 1 x $10^{6} 4 \mathrm{~T} 1$ luc cells in $0.1 \mathrm{~mL}$ of serum free DMEM with $50 \%$ Matrigel. Tumor formation was monitored for 28 days by caliper measurement. Tumor volumes were measured as indicated. Sham and WT IR: $n$ $=6$ and PRL: $n=5$. B.-C. \& F. 28 days after implantation of the cells, mice were sacrificed and total lung metastasis was quantified by bioluminescent imaging. Lung were quantified separately (B \& C) or as one (F). Sham and WT: LL and RL, $n=6$ and PRL: LL and RL, $n=5$ (B). Only lungs containing metastasis were quantified, showing significant increase in signal in right lung of PRL mice. Sham: LL, $n=5$; RL, $n=4$; WT: LL, $n=4$; RL, $n=5$; PRL: LL, $n=4$; RL, $n=4 ; * ; P=0.043$ (Man-Whitney U test) (C). D. H\&E staining of lungs from indicated groups. The metastatic areas are encircled (black). E. Quantification of the percentage of lung metastatic area calculated per mouse. Sham and WT: $n=6$ and PRL: $n=5$. 
sensitive chemoattractants released from irradiated organs, including the lung, are more migratory and metastatic [26]. Our in vitro irradiation experiment confirmed the increased release of CXCL12 and MIF upon irradiation. The heat-sensitive chemokines CXCL12 and MIF, both known to promote breast cancer metastasis, showed the highest fold change in secretion by irradiated lung epithelial cells compared to control, which was confirmed in our study $[13,27]$. The irradiation caused induction of a metastasis-receptive microenvironment that promotes trafficking and homing of cancer cells to the lung [17, 27-30]. Once the cells arrive in the lung, increased levels of CXCL12 and MIF retain the breast cancer cells in lung and provides it with survival and growth factors, so metastatic growth is enhanced [31-35]. It is not known whether CXCL12 and MIF are increased in lungs of irradiated breast cancer patients but future research could investigate the sputum, serum or urine of breast cancer patients in the acute or long-term response to radiation. Müller and co-workers were the first to demonstrate CXCR4-mediated metastasis of breast cancer cells to CXCL12-rich environments, like bone marrow, brain, lungs and liver [13]. Elevated CXCR4 expression in breast cancer cells negatively correlates with overall survival and disease-free survival in breast cancer patients and is correlated with malignant breast stem cell activity [36, 37]. Targeting this pathway could thus be a promising therapeutic addition to radiotherapy. To investigate this, we used an allosteric inhibitor of CXCR4, AMD3100 or Plerixafor $\AA$. AMD3100 was originally developed for HIV treatment and is nowadays used in combination with G-CSF as a stem cell mobilizer in patients with multiple myeloma and lymphoma [9, 13, 38-40]. Our co-culture findings showed that treatment of breast cancer cells with AMD3 100 blocks the functional and biochemical effects induced by the secretome of irradiated epithelial cells. Nevertheless, the toxic effects of AMD3100 in long-term treatment limits its clinical potential [41]. However, Peng et al. identified a small cyclic peptide (LY2510924) that inhibits CXCL12 and CXCR4 interaction and downstream signaling and function [42]. Currently, this peptide is included in clinical trials on patients with advanced cancer [43]. The CXCL12 analog peptide CTCE-9908 inhibits lung metastasis in mouse models [44, 45] and tests in Phase I/II clinical trials in cancer patients showed no major adverse effects [46]. Furthermore, the anti-CXCL12 aptamer NOX-A12 inhibits brain tumor recurrences after irradiation in rats [47]. Potentially favorable collateral inhibition of the CXCR4-CXCL12 axis may prevent lung fibrosis, improving the quality of life in breast cancer patients [48].

We are not the first to report radiotherapystimulated relapse in preclinical models. Ohuchida et al. reported that irradiation of stromal pancreatic fibroblast increased invasiveness of pancreatic cancer cell by upregulating c-Met phosphorylation and MAPK activity
[49]. Irradiation of mouse embryo fibroblasts stimulates cancer cell repopulation in cell culture and xenograft models [50]. This effect is lost when the fibroblasts are deficient for caspase-3, a key executioner of programmed cell death. Moreover, radiotherapy is not unique in inducing pro-metastatic effects in preclinical models. Comparative analysis of matched colorectal cancer specimens shows that neoadjuvant chemotherapy results in increased presence of pro-invasive $\alpha$-SMA-positive CAFs (cancer associated fibroblast) [51]. Monnier et al. demonstrated that after irradiation of the stromal bed, oral squamous cell carcinomas showed increased invasion and metastasis through the matricellular protein CYR61 [52]. Irradiation also has an effect on VEGF production and local angiogenesis, which finally contributes to metastasis formation [53].

Our results warrant further investigation of the potential pro-metastatic effects of radiation and indicate the need to develop efficient drugs which can be combined efficiently with RT in order to prevent therapy-induced spread of cancer cells. Nevertheless, the most efficient and simple solution is to prevent normal tissue irradiation. In breast cancer, the cardiopulmonary region can be spared of high doses by using multi-beam intensity-modulated radiotherapy or arc techniques, but often at the cost of a low dose spread [54]. Irradiating the breast when patients are in prone instead of supine position has been shown to spectacularly improve all lung dose-volume indices [55, 56].

\section{METHODS AND MATERIALS}

\section{Cell lines}

EA.hy926, a human endothelial cell line was obtained from ATCC (Manassas, VA, USA). MDA-MB$231 \mathrm{GFP}$ luc, a human triple-negative breast cancer cell line [57]. 4T1_luc, a mouse triple-negative breast cancer cell was obtained from Sibtech (Brookfield, CT, USA). Beas-2B cell line, a human normal lung epithelial cell line, was kindly provided by Prof. K. De Bosscher (Cytokine Receptor Lab, VIB, Ghent University). EA.hy926, MDAMB-231GFP_luc, and 4T1_luc cells were maintained in DMEM culture medium supplemented with $10 \%$ fetal bovine serum, $100 \mathrm{U} / \mathrm{mL}$ penicillin, $100 \mu \mathrm{g} / \mathrm{mL}$ streptomycin (Invitrogen, Waltham, MA, USA), and 2.5 $\mu \mathrm{g} / \mathrm{mL}$ fungizone (Bristol-Myers, Squibb, Belgium). Beas-2B cells were maintained in MEM culture medium supplemented with $0,05 \%$ L-glutamine (w/v), 10\% fetal bovine serum, $100 \mathrm{U} / \mathrm{mL}$ penicillin, $100 \mu \mathrm{g} / \mathrm{mL}$ streptomycin (Invitrogen), and $2.5 \mu \mathrm{g} / \mathrm{mL}$ fungizone. EA.hy926, 4T1_luc and Beas-2B were incubated with 5\% $\mathrm{CO}_{2}$. MDA-MB-231GFP_luc cells were incubated with $10 \% \mathrm{CO}_{2}$. Authenticity of ATCC cell lines was confirmed 
by short tandem repeat profiling in the last 6 months before use. Cell cultures were tested for mycoplasma contamination monthly by using MycoAlert Plus Kit (Lonza, Basel, Switzerland). MDA-MB-231GFP luc, GFP expression was continuously induced with doxycycline (500 ng/mL, Sigma-Aldrich, St.Louis, MO, USA). 4T1 luc were selected with Zeocine (500 $\mu \mathrm{g} / \mathrm{mL}$, Invitrogen).

\section{Antibodies and reagents}

Primary and secondary antibodies and reagents are described in Supplementary Materials and Methods.

\section{Conditioned medium of irradiated and unirradiated bronchial epithelial cells}

Normal lung epithelial cells were cultured in a 25 $\mathrm{cm}^{2}$ culture flask. Cells were irradiated using a Small Animal Radiation Research Platform, SARRP system (X-ray tube:ISOVOLT 225M2 X-ray source; SARRP system, XStrahl ${ }^{\circledR}$, Surrey, UK) at a constant rate of 3.45 $\mathrm{Gy} / \mathrm{min}$, for 174 seconds, thus receiving a single-fraction of $10.0 \mathrm{~Gy}(220 \mathrm{kV}$ and $13.0 \mathrm{~mA}$, using an $0.15 \mathrm{~mm}$ cupper filter and a $10 \times 10 \mathrm{~cm}$ collimator). Cells were positioned at a source-to-surface distance (SSD) of $34 \mathrm{~cm}$. Control "sham" samples (0 Gy) received similar handlings except for the irradiation. Conditioned medium containing soluble factors derived from irradiated epithelial cells $\left(\mathrm{CM}^{\mathrm{LE} \_\mathrm{IR}}\right)$ and medium of the sham epithelial cells $\left(\mathrm{CM}^{\mathrm{LE}}\right)$ was prepared as described in Supplementary Materials and Methods.

\section{Quantification DNA double-strand breaks (DSB)}

Quantification of $\mathrm{yH}^{\mathrm{H} 2 \mathrm{AX}}$ is used to quantify DSB. For the in vitro experiments on human Beas-2B lung epithelial cells a mouse monoclonal anti- $\mathrm{\gamma H} 2 \mathrm{AX}$ primary antibody was used in combination with an Alexa488conjugated rabbit anti-mouse secondary antibody and DAPI nuclear counterstain. The protocol as described in Depuydt et al. was followed [58]. For $\mathrm{\gamma H}^{\mathrm{H}} \mathrm{AX}$ foci analysis in the mouse lung tissue a rabbit polyclonal anti-y $\mathrm{H} 2 \mathrm{AX}$ primary antibody was used in combination with a biotinylated goat anti-rabbit secondary antibody. To visualize the foci an immunoenzymatic staining using horse radish peroxidase-conjugated streptavidin and DAB was applied followed by haematoxylin counterstaining. The protocol as described in Bolcaen et al. was followed [59]. Mice were euthanized 15 minutes after receiving thoracic sham or 10 Gy irradiation.

\section{Viability assay}

The viability was analysed with the LIVE/DEAD kit for mammalian cells (Invitrogen), as described in Supplementary Materials and Methods.

\section{Functional assays with direct cell-cell contacts}

Cell growth assay. Beas-2B cells, cultured in DMEM with $10 \%$ FBS until $70 \%$ confluency, received a sham or 10 Gy radiation. After 24 hours $1 \times 10^{3}$ MDA-MB-231GFP luc or 4T1 luc cells were added to suspended and seeded together with $2 \times 10^{5}$ sham or 10 Gy irradiated Beas-2B cells. After 4 days of co-culture, medium was changed and luciferine containing medium was added $(150 \mu \mathrm{g} / \mathrm{mL}) 2$ minutes before imaging. Imaging time was $2 \mathrm{~min} /$ cell plate. Light emitted from the breast cancer cells was detected by a highly sensitive CCD camera in the In Vivo Imaging System Lumina II (IVIS ${ }^{\circ}$, Caliper Life Science, Hopkinton, MA, USA). Analysis was achieved with Living Image ${ }^{\circledR}$ software (Caliper Life Science). There was a correlation between cell number and bioluminescence in vitro, using the In Vivo Imaging System (data not shown) [60].

Cell adhesion assay. To study the difference in adhesion of breast cancer cells to irradiated versus unirradiated epithelial cells, Beas-2B were cultured in a 6-well plate until confluency. The monolayer was sham or 10 Gy. 24 hours after treatment $2 \times 10^{4}$ MDAMB-231GFP_luc or 4T1_luc cells were added to the monolayers. To study the effect of AMD3100, a CXCR4 antagonist, cancer cells were pretreated for 30 minutes with $10 \mu \mathrm{M}$ AMD3100. In AMD3100 condition, pretreated cancer cells were added to the monolayer with a total AMD3100 concentration of $10 \mu \mathrm{M}$. Adhesion was analyzed after 24 hours using IVIS as described above.

\section{Functional assays with conditioned media}

Cell growth assay. MDA-MB-231GFP luc and $4 \mathrm{~T} 1$ luc cells $\left(2 \times 10^{4}\right)$ were seeded in a $24-$ well plate and treated either with $\mathrm{CM}^{\mathrm{LE}}{ }_{-}^{\mathrm{IR}}$ or $\mathrm{CM}^{\mathrm{LE}}$. To study the effect of recombinant CXCL12 or MIF on cancer cell growth, cells were treated with $\mathrm{CM}^{\mathrm{LE}}$ supplemented with MIF or CXCL12 (50 ng/mL). The effect of an inhibitor was studied by pretreatment of the cancer cells with 10 $\mu \mathrm{M}$ AMD3100 for 30 minutes and a total AMD3100 concentration of $10 \mu \mathrm{M}$ in $\mathrm{CM}^{\mathrm{LE} \_}{ }_{\mathrm{IR}}$. After 4 days cell numbers were analyzed by bioluminescent signal detection as described above.

Migration assay. MDA-MB-231GFP_luc cells ( $1 \times 10^{5}$ cells) were plated in the upper compartment of a Transwell chamber (24-well insert, pore size $8 \mu \mathrm{m}$, Corning Incorporated, New York, NY), while in the lower 
compartment $\mathrm{CM}^{\mathrm{LE}-\mathrm{IR}}, \mathrm{CM}^{\mathrm{LE}}$ or $\mathrm{CM}^{\mathrm{LE}}$ supplemented with CXCL12 (50 ng/mL) was used as a chemoattractant. To study the effect of AMD3100, cancer cells were pretreated 30 minutes with $10 \mu \mathrm{M}$ AMD3100, and AMD3100 was added in both compartments in $\mathrm{CM}^{\mathrm{LE}-\mathrm{IR}}$ with a final 10 $\mu \mathrm{M}$ concentration. Migration was stopped after 8 hours incubation and the insert was washed with $\mathrm{PBS}^{\mathrm{D}+}$. Cells from the apical side were removed using a cotton swab before fixation with ice-cold methanol and DAPI staining. After 4 washing steps with PBS $^{\mathrm{D}-}$, the filter was mounted onto glass using glycergel mounting medium (Dako, Carpinteria, CA, USA). Cell nuclei were analyzed by counting 6 different, randomly chosen fields with a 10x objective on a Zeiss Axiovert 200M fluorescent microscope.

Transendothelial migration assay. Formation and analysis of endothelial monolayer is described in Supplementary Materials and Methods and Supplementary Figure S7.

Doxycycline-induced MDA-MB-231GFP luc cells $\left(1 \times 10^{5}\right)$ were added on top of the endothelial cells. $\mathrm{CM}^{\mathrm{LE} \_I R}, \mathrm{CM}^{\mathrm{LE}}$ or $\mathrm{CM}^{\mathrm{LE}}{ }_{-} \mathrm{IR}+\mathrm{AMD} 3100$ were used as a chemoattractant. After incubation for 24 hours the apical side of the chamber was washed twice with PBSD+ and scraped gently with a cotton swap. Migrated cancer cells, green fluorescent, were counted from 8 different, randomly chosen fields with a 10x objective on a Zeiss Axiovert 200M fluorescent microscope (Carl Zeiss, Micro-imaging, Heidelberg, Germany).

Morphology analysis. For quantification of morphological changes, 2 x $10^{5}$ MDA-MB-231GFP_luc single cells were seeded on glass cover slips in presence of control medium or $\mathrm{CM}^{\mathrm{LE}} \mathrm{IR}$. After 4 days of incubation, cells were fixed with $3.7 \%$ formaldehyde for 20 minutes. Permeabilization with $0,1 \%$ Triton-X100 was done for 5 minutes and cells were blocked for 30 minutes, while shaking, with $1 \%$ BSA. Next, glasses were stained with F-actin stain phalloidin-Alexa Fluor 594 and DAPI and imaged with a Zeiss Axiovert 200M fluorescent microscope. Of each condition, 20 cells from 4 different glasses were used to score factor shape with the formula: (perimeter $)^{2} /(4 \times \pi \times$ area $)$.

\section{Protein analysis}

SDS-PAGE and Western blot analysis. Lysate preparation, SDS-PAGE and Western blot analysis are described in Supplementary Materials and Methods.

Cytokine array. RayBio®Label-Based human antibody array 507 (L-507, RayBiotech Inc., Norcross, GA, USA) was used to identify the cytokines playing a key role in the effect of irradiated bronchial epithelial cells. Cytokine array analysis is described in Supplementary Materials and Methods.

ELISA analysis. CXCL12 and MIF secretion levels were measured using quantitative immunometric sandwich enzyme immunoassays (ELISA = enzyme-linked immunosorbent assay), following the manufacturer's recommended procedures ( $\mathrm{R} \&$ D Systems, Minneapolis, MN, USA). Optical density was measured at $450 \mathrm{~nm}$ of wavelength, with correction set to $570 \mathrm{~nm}$, on a PARADIGM ${ }^{\mathrm{TM}}$ Microplate Detection Platform (Beckman Coulter, Brea, CA, USA). Triplicate cultures of cells were tested for each experimental condition.

\section{Animal studies}

Radiotherapy treatment planning. In this study, two different dose plans were set up and executed on the SARRP. One delivered 10Gy to the entire thorax, the other delivered 10 Gy to $10 \%$ volume of the right lung. First, dose distributions was calculated using the on-board CT as described earlier [61]. 4-week-old BALB/c female mice (Charles River, L'Abresle, France), were anesthetized, fixed on a plastic bed and placed on a holder secured onto the robotic positioning table. Cone-beam (CB) CT imaging is achieved by rotating the stage that supports the animal, horizontally between the stationary X-ray source and a flat-panel detector. The uncollimated primary beam, $20 \mathrm{~cm} \times 20 \mathrm{~cm}$ at isocenter, is used for imaging. X-rays of $70 \mathrm{kV}$ emitted from the $0.4 \mathrm{~mm}$ focal spot and filtered by $1 \mathrm{~mm}$ thick aluminum were employed. Images were acquired at a current of $1 \mathrm{~mA}$, with "continuous" beamon as well as "continuous" stage rotation. Three hundred and sixty (360) projections were acquired over $360^{\circ}$. Second, the treatment isocenter was placed in the lower part of the right hemisphere of the lung. For whole thorax treatment, two posterior-anterior beams, with a size of 9 $\mathrm{x} 3 \mathrm{~mm}$ and $10 \times 10 \mathrm{~mm}$ at isocenter, were used to cover the entire thorax (Supplementary Figure S5B). Treatment isocenter was set for both in the middle of both lungs. One posterior-anterior beam with a size of $3 \times 3 \mathrm{~mm}$ was selected to irradiate $18 \mathrm{~mm}^{3}$ of the right lung with $10 \mathrm{~Gy}$, which resembles approximately $10 \%$ volume of the right lung $(8,57 \%$ calculation based on Knuts et al. [62]) (Supplementary Figure S5A, S5C). The CT scans are imported into Muriplan software (Xstrahl®). Next, image intensity-based tissue segmentation was performed to allow correct dose calculation throughout the different tissue densities. The voltage of the $\mathrm{X}$-ray source is fixed at $220 \mathrm{kV}$ with a tube current of $12 \mathrm{~mA}$, emitted from the $3.0 \mathrm{~mm}$ focal spot and filtered by a copper filter of $0.15 \mathrm{~mm}$. Mice with sham treatment only underwent the imaging part.

4T1_luc triple-negative mouse breast cancer model. All mice were orthotopically injected 24 hours after radiation treatment. One million 4T1_luc cells, suspended in a $100 \mu \mathrm{L}$ mixture of serum-free DMEM and Matrigel (1:1), were injected into the mammary fat pad. The primary tumor volume was quantified as the product of caliper measurements of the longest and the shortest tumor diameter $(\mathrm{V}=0,4 \times$ (longest 
axis) $\mathrm{x}$ (shortest axis $)^{2}$ ). Primary and metastatic tumor growths were monitored by bioluminescence. First, mice were giving an intraperitoneaal injection of $100 \mu \mathrm{L}$ D-luciferin in PBS $(150 \mu \mathrm{g} / \mathrm{g}$ mouse $)$. Then, animals were anesthetized with 5\% isoflurane in oxygen for induction and $1.5 \%$ isoflurane in oxygen for maintenance. Next, bioluminescent imaging was initiated 10 minutes after injection by a cooled CCD camera in the IVIS with a 15$\mathrm{cm}$ field of view, binning factor of $8,1 /$ f stop and open filter. Exposure times were set automatically, depending on the luciferase signaling activity. ROIs were drawn for primary tumor and metastatic lesions and were calculated by the IVIS software, expressed in total flux (photon/s). Background photon flux was defined, for primary growth on a blanc mouse and for metastatic lesions on a normal lung, and extracted from all animal values. Images were initiated every 4 days after inoculation. After 4 weeks, mice were sacrificed and tumor and lungs were resected. Lungs were placed into 6-well plates and ex vivo bioluminescent imaging was performed by adding 300 $\mu \mathrm{g} / \mathrm{mL} \mathrm{D}$-luciferin in excess. After imaging, all tissues were fixed in $4 \%$ buffered formalin. H\&E staining and immunohistochemistry were performed using a NexES automated slide staining system (Ventana Medical Systems, Tucson, AZ) on paraffin sections. Animals were treated according to the European guidelines on animal experiments (2010/63/EU). They were kept in 12h lightdark cycles, with ad libitum access to food and water. Animal studies were approved by the Animal Ethics Committee of Ghent University, Belgium (ECD 10/36).

\section{Statistical analysis}

Statistical analysis was performed using GraphPad Prism and confirmed by IBM SPSS Statistics 21.0 software. D'Agostino-Pearson was used for testing normal distribution. Normal distributed data were analyzed using unpaired $t$-test, adjusted with Welch's correction when variance was statistically different. All nonparametric data were analyzed using Mann-Whitney $U$ test. All values in box- and whisker blots are expressed as the mean and 95\% confidence interval. All other values are expresses as the mean $\pm \mathrm{SD}$. A $P$ value of $<0.05$ was considered statistically significant. Statistical tests were two -sided. All data are representative of at least three independent experiments.

\section{ACKNOWLEDGMENTS}

The authors would like to thank $M$. De Meulemeester, S. Decloedt, K. Van Wesenmael, S. De Geyter and L. Pieters for the technical assistance.

\section{FUNDINGS}

This research was supported by Stichting Emmanuel van der Schueren (Kom op tegen Kanker). L.F was supported by Association Research of Ghent University and HoGent (05V03011).

\section{CONFLICTS OF INTERESTS}

There are no conflicts of interests.

\section{Abbreviations}

a-SMA: Alfa smooth muscle actin

Akt: $\quad$ Protein kinase B

AMD3100: $\quad$ 1,1'-[1,4-Phenylenebis(methyl

ene)]bis[1,4,8,11-tetraazacyclotetradecane]

BALB: Bagg Albino

BSA: Bovine serum albumin

CAF: $\quad$ Cancer-associated fibroblast

CCD: $\quad$ Charge coupled device

c-Met: Cellular mesenchymal to epithelial

transition factor

CMLE: Conditioned medium lung epithelial cells

CMLE-IR: Conditioned medium irradiated lung epithelial cells

CT: $\quad$ Computed tomography

CXCL12: C-X-C chemokine ligand 12

CXCR4: C-X-C chemokine receptor 4

CYR61: Cysteine-rich angiogenic inducer 61

DAB: $\quad 3,3$ '-diaminobenzidine

tetrahydrochloride hydrate

DAPI: 4',6-diamidino-2-phenylindole

DiI: $\quad$ 1,1'-dioctadecyl-3,3,3'3'-

tetramethylindocarbocyanine perchlorate

DMEM: Dulbecco's Modified Eagle's medium

DSB: $\quad$ Double strand break

ELISA: Enzyme-linked immunosorbent assay

ERK: $\quad$ Extracellular Signal-Regulated Kinase

GAPDH: Glyceraldehyde-3-phosphate

dehydrogenase

G-CSF: Granulocyte colony-stimulating factor

GFP: Green fluorescent protein

Gy: Unit of absorbed dose and equivalent to

$1 \mathrm{~J} / \mathrm{kg}$

H2AX: Histone 2A, member X

IVIS: In vivo imaging system

MAPK: Mitogen-activated protein kinase

MEK1/2: Mitogen-activated protein kinase/ extracellular signal-regulated kinase kinase 1/2

MIF: $\quad$ Macrophage migration inhibitory factor

PBS D- : Phosphate-buffered saline without calcium and magnesium

PBS D+: Phosphate-buffered saline supplemented 
with calcium and magnesium

PRL: $\quad$ Partial right lung

ROI: $\quad$ Region of interest

RT: $\quad$ Radiation treatment/Radiotherapy

SARRP: Small animal radiation research

platform

SD: $\quad$ Standard deviation

SDF-1: $\quad$ Stromal cell-derived factor 1

SPSS: $\quad$ Statistical package for the social science

STAT3: Signal transducer and activator of

transcription 3

WT: Whole thorax

\section{REFERENCES}

1. Goldhirsch A, Wood WC, Coates AS, Gelber RD, Thürlimann B and Senn HJ. Strategies for subtypes-dealing with the diversity of breast cancer: highlights of the St. Gallen International Expert Consensus on the Primary Therapy of Early Breast Cancer 2011. Ann Oncol. 2011; 22:1736-1747.

2. McGale P, Taylor C, Correa C, Cutter D, Duane F, Ewertz M, Gray R, Mannu G, Peto R, Whelan T, Wang Y, Wang Z and Darby $\mathrm{S}$. Effect of radiotherapy after mastectomy and axillary surgery on 10-year recurrence and 20-year breast cancer mortality: meta-analysis of individual patient data for 8135 women in 22 randomised trials. The Lancet. 2014; 383:2127-2135.

3. Moran MS. Radiation therapy in the locoregional treatment of triple-negative breast cancer. The Lancet Oncology. 2015; 16:113-122.

4. Clarke M, Collins R, Darby S, Davies C, Elphinstone P, Evans E, Godwin J, Gray R, Hicks C, James S, MacKinnon E, McGale P, McHugh T, Peto R, Taylor C, Wang Y, et al. Effects of radiotherapy and of differences in the extent of surgery for early breast cancer on local recurrence and 15-year survival: an overview of the randomised trials. The Lancet. 2005; 366:2087-2106.

5. Darby S, McGale P, Correa C, Taylor C, Arriagada R, Clarke M, Cutter D, Davies C, Ewertz M, Godwin J, Gray R, Pierce L, Whelan T, et al. Early Breast Cancer Trialists' Collaborative Group (EBCTCG). Effect of radiotherapy after breast-conserving surgery on 10-year recurrence and 15-year breast cancer death: meta-analysis of individual patient data for 10801 women in 17 randomised trials. The Lancet. 2011; 378:1707-1716.

6. Vicini F, Kestin L, Huang R and Martinez A. Does local recurrence affect the rate of distant metastases and survival in patients with early-stage breast carcinoma treated with breast-conserving therapy? Cancer. 2003; 97:910-919.

7. Kuonen F, Laurent J, Secondini C, Lorusso G, Stehle JC, Rausch T, Faes-Van't Hull E, Bieler G, Alghisi GC, Schwendener R, Andrejevic-Blant S, Mirimanoff RO and Ruegg C. Inhibition of the Kit ligand/c-Kit axis attenuates metastasis in a mouse model mimicking local breast cancer relapse after radiotherapy. Clin Cancer Res. 2012; 18:43654374.

8. Wang Y, Li W, Patel SS, Cong J, Zhang N, Sabbatino F, Liu X, Qi Y, Huang P, Lee H, Taghian A, Li J-J, DeLeo $\mathrm{AB}$, et al. Blocking the formation of radiation-induced breast cancer stem cells. Oncotarget. 2014; 5:3743-3755.

9. Darby S, Ewertz M, McGale P, Bennet A, Blom Goldman U, Brønnum D, Correa C, Cutter D, Gagliardi G, Gigante B, Jensen M-B, Nisbet A, Peto R, et al. Risk of ischemic heart disease in women after radiotherapy for breast cancer. N Engl J Med. 2013; 368:987-998.

10. Inskip PD, Stovall M and Flannery JT. Lung cancer risk and radiation dose among women treated for breast cancer. J Natl Cancer Inst. 1994; 86:983-988.

11. Jaén J, Vázquez G, Alonso E, De Las Peñas MD, Díaz L, De Las Heras M and Pérez-Regadera JF. Long-term Changes in Pulmonary Function After Incidental Lung Irradiation for Breast Cancer: A Prospective Study With 7-Year Followup. Int J Radiat Oncol Biol Phys. 2012; 84:565-570.

12. Kimsey FC, Mendenhall NP, Ewald LM, Coons TS and Layon AJ. Is radiation treatment volume a predictor for acute or late effect on pulmonary function? A prospective study of patients treated with breast-conserving surgery and postoperative irradiation. Cancer. 1994; 73:2549-2555.

13. Müller A, Homey B, Soto H, Ge N, Catron D, Buchanan ME, McClanahan T, Murphy E, Yuan W, Wagner SN, Barrera JL, Mohar A, Verástegui E and Zlotnik A. Involvement of chemokine receptors in breast cancer metastasis. Nature. 2001; 410:50-56.

14. Hart Y, Antebi YE, Mayo AE, Friedman N and Alon U. Design principles of cell circuits with paradoxical components. Proc Natl Acad Sci U S A. 2012; 109:83468351.

15. Zhang XHF, Jin X, Malladi S, Zou Y, Wen YH, Brogi E, Smid M, Foekens J and Massagué J. Selection of bone metastasis seeds by mesenchymal signals in the primary tumor stroma. Cell. 2013; 154:1060-1073.

16. Neve RM, Chin K, Fridlyand J, Yeh J, Baehner FL, Fevr T, Clark L, Bayani N, Coppe J-P, Tong F, Speed T, Spellman PT, DeVries S, Lapuk A, Wang NJ, Kuo W-L, et al. A collection of breast cancer cell lines for the study of functionally distinct cancer subtypes. Cancer Cell. 2006; 10:515-527.

17. Teicher B and Fricker S. CXCL12 (SDF-1)/CXCR4 pathway in cancer. Clin Cancer Res. 2010; 16:2927-2931.

18. Jing J, Greshock J, Holbrook J, Gilmartin A, Zhang X, McNeil E, Conway T, Moy C, Laquerre S, Bachman K, Wooster R and Degenhardt Y. Comprehensive predictive biomarker analysis for MEK inhibitor GSK1120212. Mol Cancer Ther. 2012; 11:720-729.

19. Foulkes W, Smith I and Reis Filho J. Triple-negative breast cancer. T N Engl J Med. 2010; 363:1938-1948.

20. Yagata H, Kajiura Y and Yamauchi H. Current strategy for triple-negative breast cancer: appropriate combination of 
surgery, radiation, and chemotherapy. Breast Cancer. 2011; 18:165-173.

21. Nielsen HM, Overgaard M, Grau C and Jensen AR. Study of failure pattern among high-risk breast cancer patients with or without postmastectomy radiotherapy in addition to adjuvant systemic therapy: long-term results from the Danish Breast Cancer Cooperative Group DBCG 82 b and c randomized studies. J Clin Oncol. 2006; 24:2268-2275.

22. Weigelt B, Peterse JL and van 't Veer LJ. Breast cancer metastasis: markers and models. Nat Rev Cancer. 2005; 5:591-602.

23. Psaila B and Lyden D. The Metastatic Niche: Adapting the Foreign Soil. Nat Rev Cancer. 2009; 9:285-293.

24. Ivashkevich A, Redon CE, Nakamura AJ and Martin RF. Use of the $\gamma$-H2AX assay to monitor DNA damage and repair in translational cancer research. Cancer Lett. 2012; 327:123-133.

25. Kunwar A and Haston CK. DNA damage at respiratory distress, but not acute time-points, correlates with tissue fibrosis following thoracic radiation exposure in mice. Int $\mathrm{J}$ Radiat Biol. 2015; 91:360-367.

26. Gunjal P, Schneider G, Ismail A, Kakar S, Kucia M and Ratajczak M. Evidence for induction of a tumor metastasisreceptive microenvironment for ovarian cancer cells in bone marrow and other organs as an unwanted and underestimated side effect of chemotherapy/radiotherapy. J Ovarian Res. 2015; 8:20.

27. Verjans E, Noetzel E, Bektas N, Schütz AK, Lue H, Lennartz B, Hartmann A, Dahl E and Bernhagen J. Dual role of macrophage migration inhibitory factor (MIF) in human breast cancer. BMC Cancer. 2009; 9:230-230.

28. Chiang A and Massagué J. Molecular basis of metastasis. T N Engl J Med. 2008; 359:2814-2823.

29. Shin H-N, Moon H-H and Ku J-L. Stromal cell-derived factor- $1 \alpha$ and macrophage migration-inhibitory factor induce metastatic behavior in CXCR4-expressing colon cancer cells. Int J Mol Med. 2012; 30:1537-1543.

30. Sarvaiya PJ, Guo D, Ulasov I, Gabikian P and Lesniak MS. Chemokines in tumor progression and metastasis. Oncotarget. 2013; 4:2171-2185.

31. Nguyen DX, Bos PD and Massague J. Metastasis: from dissemination to organ-specific colonization. Nat Rev Cancer. 2009; 9:274-284.

32. Smith MCP, Luker KE, Garbow JR, Prior JL, Jackson E, Piwnica-Worms D and Luker GD. CXCR4 Regulates Growth of Both Primary and Metastatic Breast Cancer. Cancer Res. 2004; 64:8604-8612.

33. Zeelenberg IS, Ruuls-Van Stalle L and Roos E. The Chemokine Receptor CXCR4 Is Required for Outgrowth of Colon Carcinoma Micrometastases. Cancer Res. 2003; 63:3833-3839.

34. Darash-Yahana M, Pikarsky E, Abramovitch R, Zeira E, Pal B, Karplus R, Beider K, Avniel S, Kasem S, Galun E and Peled A. Role of high expression levels of CXCR4 in tumor growth, vascularization, and metastasis. FASEB J. 2004; 18:1240-1242.

35. Zlotnik A, Burkhardt A and Homey B. Homeostatic chemokine receptors and organ-specific metastasis. Nat Rev Immunol. 2011; 11:597-606.

36. Xu T-P, Shen H, Liu L-X and Shu Y-Q. The impact of chemokine receptor CXCR4 on breast cancer prognosis: a meta-analysis. Cancer Epidemiol. 2013; 37:725-731.

37. Ablett MP, O'Brien CS, Sims AH, Farnie G and Clarke RB. A differential role for CXCR4 in the regulation of normal versus malignant breast stem cell activity. Oncotarget. 2014; 5:599-612.

38. Andreola G, Babic A, Rabascio C, Negri M, Martinelli $\mathrm{G}$ and Laszlo D. Plerixafor and Filgrastim XM02 (Tevagastrim) as a first line peripheral blood stem cell mobilisation strategy in patients with multiple myeloma and lymphoma candidated to autologous bone marrow transplantation. Eur J Haematol. 2012; 88:154-158.

39. De Clercq E. Recent advances on the use of the CXCR4 antagonist plerixafor (AMD3100, Mozobil ${ }^{\mathrm{TM}}$ ) and potential of other CXCR4 antagonists as stem cell mobilizers. Pharmacol Ther. 2010; 128:509-518.

40. Donzella GA, Schols D, Lin SW, Esté JA, Nagashima KA, Maddon PJ, Allaway GP, Sakmar TP, Henson G, De Clercq E and Moore JP. AMD3100, a small molecule inhibitor of HIV-1 entry via the CXCR4 co-receptor. Nat Med. 1998; 4:72-77.

41. Hendrix C, Collier A, Lederman M, Schols D, Pollard R, Brown S, Jackson JB, Coombs R, Glesby M, Flexner C, Bridger G, Badel K, MacFarland R, Henson G and Calandra G. Safety, pharmacokinetics, and antiviral activity of AMD3100, a selective CXCR4 receptor inhibitor, in HIV-1 infection. J Acquir Immune Defic Syndr. 2004; 37:12531262.

42. Peng S-B, Zhang X, Paul D, Kays L, Gough W, Stewart J, Uhlik M, Chen Q, Hui Y-H, Zamek Gliszczynski M, Wijsman J, Credille $\mathrm{K}$ and Yan L. Identification of LY2510924, a novel cyclic peptide CXCR4 antagonist that exhibits antitumor activities in solid tumor and breast cancer metastatic models. Mol Cancer Ther. 2015; 14:480490.

43. Galsky M, Vogelzang N, Conkling P, Raddad E, Polzer J, Roberson S, Stille J, Saleh M and Thornton D. A phase I trial of LY2510924, a CXCR4 peptide antagonist, in patients with advanced cancer. Clinical Cancer Res. 2014; 20:3581-3588.

44. Huang E, Singh B, Cristofanilli M, Gelovani J, Wei C, Vincent L, Cook K and Lucci A. A CXCR4 antagonist CTCE-9908 inhibits primary tumor growth and metastasis of breast cancer. J Surg Res. 2009; 155:231-236.

45. Hassan S, Buchanan M, Jahan K, Aguilar Mahecha A, Gaboury L, Muller W, Alsawafi Y, Mourskaia A, Siegel $\mathrm{P}$, Salvucci O and Basik M. CXCR4 peptide antagonist inhibits primary breast tumor growth, metastasis and 
enhances the efficacy of anti-VEGF treatment or docetaxel in a transgenic mouse model. Int J Cancer. 2011; 129:225232.

46. Hotte S, Hirte H, Iacobucci A, Wong D, Cantin L, Korz W and Miller W. Phase I/II study of CTCE-9908, a novel anticancer agent that inhibits CXCR4, in patients with advanced solid cancers. Mol Cancer Ther. 2007; 6:A153-A153.

47. Liu S-C, Alomran R, Chernikova S, Lartey F, Stafford J, Jang T, Merchant M, Zboralski D, Zöllner S, Kruschinski A, Klussmann S, Recht L and Brown JM. Blockade of SDF-1 after irradiation inhibits tumor recurrences of autochthonous brain tumors in rats. Neuro Oncol. 2014; 16:21-28.

48. Shu H-K, Yoon Y, Hong S, Xu K, Gao H, Hao C, Torres Gonzalez E, Nayra C, Rojas M and Shim H. Inhibition of the CXCL12/CXCR4-axis as preventive therapy for radiation-induced pulmonary fibrosis. PloS One. 2013; 8:e79768.

49. Ohuchida K. Radiation to Stromal Fibroblasts Increases Invasiveness of Pancreatic Cancer Cells through TumorStromal Interactions. Cancer Res. 2004; 64:3215-3222.

50. Huang Q, Liu X, Shi W, O'Sullivan B, He Z, Peng Y, Tan A-C, Zhou L, Shen J, Han G, Wang X-J, Thorburn J, Jimeno A, Raben D, Bedford JS and Li C-Y. Caspase 3-mediated stimulation of tumor cell repopulation during cancer radiotherapy. Nature Med. 2011; 17:860-866.

51. Lotti F, Jarrar AM, Pai RK, Hitomi M, Lathia J, Mace A, Gantt GA, Sukhdeo K, DeVecchio J, Vasanji A, Leahy P, Hjelmeland AB, Kalady MF and Rich JN. Chemotherapy activates cancer-associated fibroblasts to maintain colorectal cancer-initiating cells by IL-17A. J Exp Med. 2013; 210:2851-2872.

52. Monnier Y, Farmer P, Bieler G, Imaizumi N, Sengstag T, Alghisi GC, Stehle JC, Ciarloni L, Andrejevic-Blant S, Moeckli R, Mirimanoff RO, Goodman SL, Delorenzi M and Ruegg C. CYR61 and alphaVbeta5 integrin cooperate to promote invasion and metastasis of tumors growing in preirradiated stroma. Cancer Res. 2008; 68:7323-7331.

53. Vala SI, Martins L, Imaizumi N, Nunes R, Rino J, Kuonen F, Carvalho L, Rüegg C, Grillo I, Barata J, Mareel M and Santos SCR. Low doses of ionizing radiation promote tumor growth and metastasis by enhancing angiogenesis. PloS One. 2010; 5:e11222.

54. Beckham WA, Popescu CC, Patenaude VV, Wai ES and Olivotto IA. Is multibeal IRT better than standard treatment for patients with left-sidd breast cancer? Int J Radiat Oncol Biol Phys. 2007; 69:918-924.

55. Mulliez T, Veldeman L, van Greveling A, Speleers B, Sadeghi S, Berwouts D, Decoster F, Vercauteren T, De Gersem W, Van den Broecke R and De Neve W. Hypofractionated whole breast irradiation for patients with large breasts: A randomized trial comparing prone and supine positions. Radiother Oncol. 2013; 108:203-208.

56. Kirby AM, Evans PM, Donovan EM, Convery HM,
Haviland JS and Yarnold JR. Prone versus supine positioning for whole and partial-breast radiotherapy: A comparison of non-target tissue dosimetry. Radiother Oncol. 2010; 96:178-184.

57. Van Impe K, Bethuyne J, Cool S, Impens F, Ruano Gallego D, De Wever O, Vanloo B, Van Troys M, Lambein K, Boucherie C, Martens E, Zwaenepoel O, Hassanzadeh Ghassabeh G, Vandekerckhove J, Gevaert K, Fernández LÁ, et al. A nanobody targeting the F-actin capping protein CapG restrains breast cancer metastasis. Breast Cancer Res. 2013; 15:R116.

58. Depuydt J, Baert A, Vandersickel V, Thierens H and Vral A. Relative biological effectiveness of mammography X-rays at the level of DNA and chromosomes in lymphocytes. Int J Radiat Biol. 2013; 89:532-538.

59. Bolcaen J, Descamps B, Deblaere K, Boterberg T, Hallaert G, Van den Broecke C, Decrock E, Vral A, Leybaert L, Vanhove C and Goethals I. MRI-guided 3D conformal arc micro-irradiation of a F98 glioblastoma rat model using the Small Animal Radiation Research Platform (SARRP). J Neurooncol. 2014; 120:257-266.

60. Jenkins D, Oei Y, Hornig Y, Yu S-F, Dusich J, Purchio T and Contag P. Bioluminescent imaging (BLI) to improve and refine traditional murine models of tumor growth and metastasis. Clin Exp Metastasis. 2003; 20:733-744.

61. Wong J, Armour E, Kazanzides P, Iordachita I, Tryggestad E, Deng H, Matinfar M, Kennedy C, Liu Z, Chan T, Gray O, Verhaegen F, McNutt T, Ford E and DeWeese T. Highresolution, small animal radiation research platform with $\mathrm{x}$-ray tomographic guidance capabilities. Int J Radiat Oncol Biol Phys. 2008; 71:1591-1599.

62. Knust J, Ochs M, Gundersen HJG and Nyengaard J. Stereological estimates of alveolar number and size and capillary length and surface area in mice lungs. Anat Rec. 2009; 292:113-122. 